\title{
Investigation of Rotor Performance and Loads of a UH-60A Individual Blade Control System
}

\author{
Hyeonsoo Yeo \\ Aeroflightdynamics Directorate (AMRDEC) \\ U.S. Army Research, Development, and Engineering Command \\ Ames Research Center, Moffett Field, California
}

\author{
Ethan A. Romander \\ Thomas R. Norman \\ Flight Vehicle Research and Technology Division \\ NASA Ames Research Center \\ Moffett Field, California
}

\begin{abstract}
Wind tunnel measurements of performance, loads, and vibration of a full-scale UH-60A Black Hawk main rotor with an individual blade control (IBC) system are compared with calculations obtained using the comprehensive helicopter analysis CAMRAD II and a coupled CAMRAD II/OVERFLOW 2 analysis. Measured data show a $5.1 \%$ rotor power reduction ( $8.6 \%$ rotor lift to effective-drag ratio increase) using $2 / \mathrm{rev}$ IBC actuation with $2.0^{\circ}$ amplitude at $\mu=0.4$. At the optimum IBC phase for rotor performance, IBC actuator force (pitch link force) decreased, and neither flap nor chord bending moments changed significantly. CAMRAD II predicts the rotor power variations with IBC phase reasonably well at $\mu=0.35$. However, the correlation degrades at $\mu=0.4$. Coupled CAMRAD II/OVERFLOW 2 shows excellent correlation with the measured rotor power variations with IBC phase at both $\mu=0.35$ and $\mu=0.4$. Maximum reduction of IBC actuator force is better predicted with CAMRAD II, but general trends are better captured with the coupled analysis. The correlation of vibratory hub loads is generally poor by both methods, although the coupled analysis somewhat captures general trends.
\end{abstract}

\section{Introduction}

A full-scale wind tunnel test was recently conducted (March 2009) in the National Full-Scale Aerodynamics Complex (NFAC) 40- by 80-Foot Wind Tunnel to evaluate the potential of an individual blade control (IBC) system to improve rotor performance and reduce loads, vibrations, and noise for a UH-60A rotor system [1]. This test was the culmination of a long-term collaborative effort between NASA, U.S. Army, Sikorsky Aircraft Corporation, and ZF Luftfahrttechnik $\mathrm{GmbH}$ (ZFL) to demonstrate the benefits of IBC for a UH$60 \mathrm{~A}$ rotor. Figure 1 shows the rotor and IBC system mounted on the NFAC Large Rotor Test Apparatus (LRTA).

The IBC concept used in the current study replaced the pitch link for each rotor blade with an actuator so that the blade root pitch angles could be changed independently. This design was previously tested in the NFAC 80 - by 120 -Foot Wind Tunnel in September 2001 at speeds up to 85 knots [2]. For the current test, the same UH-60A rotor and IBC system were tested in the 40 - by 80 -Foot Wind Tunnel at speeds up to 170 knots. Figure 2 shows the servo-hydraulic IBC actuator installed between the swashplate and the blade pitch horn.

The concept of using individual blade pitch control inputs to reduce helicopter vibration, noise, and power has been extensively studied over the last two decades. Early research

Presented at the American Helicopter Society 66th Annual Forum, Phoenix, Arizona, May $11-13$, 2010. This material is declared a work of the U.S. Government and is not subject to copyright protection. focused on the potential vibration reduction from an IBC system, including a flight test on a BO-105 helicopter [3,4]. With more powerful IBC systems available, researchers began to investigate potential rotor performance improvement as well as noise and vibration reductions. Full-scale BO-105 rotor tests conducted in the NFAC 40- by $80-$ Foot Wind Tunnel $[5,6]$ demonstrated that helicopter noise and vibration can be simultaneously reduced by up to $85 \%$ using $2 /$ rev IBC in combination with other IBC harmonics. In addition, $2 / \mathrm{rev}$ IBC was shown to reduce rotor power by up to $7 \%$ at high-speed flight conditions. It should be noted that rotor propulsive force was not trimmed during this test. Flight tests of a $\mathrm{CH}-53 \mathrm{G}$ helicopter showed up to $6 \%$ reduction of effective rotor power using $0.67^{\circ} 2 / \mathrm{rev}$ IBC, along with reduction in pitch link loads [7].

In contrast with some of these earlier experiments, the current test included propulsive force as a trim target, incorporating a closed-loop trim control system to automatically adjust the fixed-system controls to match specific rotor conditions. This ensured that any measured power reduction was caused by the IBC input and not the change in rotor trim. Thus, the current test provides a unique resource that can be used to assess the accuracy and reliability of prediction methods and refine theoretical models, with the ultimate goal of providing the technology for timely and cost-effective design and development of new rotors.

Analytical studies on IBC [8-10] have also shown the 
promise to improve the rotor's performance using $2 / \mathrm{rev}$ inputs. However, in-depth correlation studies have not been performed. In recent years, there has been significant progress in aeromechanics prediction capability using coupled computational fluid dynamics (CFD) / rotorcraft computational structural dynamics (CSD) analyses $[11,12]$. The CFD methods, which use a high fidelity, Navier-Stokes, overset grid methodology with first-principles-based wake capturing, overcame the limitations of the conventional lifting line aerodynamics used in rotorcraft comprehensive codes. Researchers have begun to use these methods to investigate various active control schemes such as trailing edge flap, leading edge droop, and active twist [13-16]. These studies helped provide better understanding of the benefits of various active control concepts and the physics behind them. Again, no in-depth correlation studies have been performed.

The purpose of this paper is to perform an extensive correlation study of a comprehensive rotorcraft analysis and a CFD/CSD coupled analysis with UH-60A/IBC wind tunnel test data. In particular, the focus of this paper is the influence of $2 / \mathrm{rev}$ IBC inputs on rotor performance, loads, and vibration.

\section{Description of the Test}

The experiment was conducted in the NFAC 40- by 80 -Foot Wind Tunnel using a Sikorsky Aircraft UH-60A rotor system mounted on the NFAC LRTA. A detailed description of the experiment can be found in Ref. 1, including information on the test hardware, instrumentation, data acquisition and reduction systems, rotor control systems, and standard test procedures. Information pertinent to the current study is provided below.

The rotating hardware was predominantly UH-60A flight hardware, with the exception of the instrumentation hat and those components necessary for IBC actuator operation. In addition, the normal UH-60 bifilar weights were not installed so the effects of IBC on vibration could be studied in isolation. The UH-60A is a four-bladed rotor with coincident flap and lag articulation provided at the blade root by elastomeric bearings. This bearing, through the rotor spindle, also allows for blade pitch motion. As stated earlier, the normally rigid pitch links were replaced by servohydraulic IBC actuators for this test. These actuators allowed the pitch of the rotor blades to be changed independently of each other. References 1 and 17 provide a full discussion of the actuator characteristics, the automatic emergency shutdown feature, the development program, qualification testing, and the installation onto the LRTA.

The primary test measurements used for comparisons in this paper include static and dynamic hub loads, rotor power, blade loads, IBC actuator displacements, and IBC actuator forces. The hub loads and rotor power were obtained from the LRTA five-component balance and flex coupling. The balance measures rotor normal, axial and side forces, together with the rotor pitching and rolling moments. The instrumented flex coupling measures rotor torque and residual power-train normal force. The rotor hub loads had aerodynamic tares (aerodynamic loads measured with no blades installed) subtracted to better simulate isolated rotor forces and moments. Both the rotor balance and flex coupling were designed to measure static and dynamic loads. Although only calibrated statically for this program, relative changes in the measured dynamic loads can still be used to evaluate the effects of IBC input. Blade loads were obtained from calibrated strain gages located at specific blade radial locations. IBC actuator displacements were measured with in-line LVDTs (Linear Variable Differential Transducers) and actuator forces (equivalent to pitch link loads) were measured with calibrated strain gages.

Data from two different advance ratios were used in this study (see Table 1). At each advance ratio, IBC phase and amplitude sweeps were conducted using $2 /$ rev IBC inputs, defined as

$$
\theta=\mathrm{A} \cos (2 \psi-\phi)
$$

where $\theta$ is the IBC equivalent blade pitch, $\mathrm{A}$ is the amplitude of the $2 / \mathrm{rev}$ IBC, $\psi$ is the blade azimuth angle, and $\phi$ is the phase angle of the $2 / \mathrm{rev}$ IBC. It should be noted that the IBC pitch inputs are derived from the actuator displacements measured during the test, and are not the direct measure of blade pitch at the spherical bearing. Because of control system flexibilities, actual blade pitch changes due to IBC can be different than a simple geometric calculation may suggest.

For the test conditions considered in this study, the rotor was trimmed to non-dimensional rotor lift, propulsive force and hub rolling moment, with the rotor shaft angle of attack fixed. The hub pitching moment was not controlled or used for feedback. The IBC actuator motion was controlled in openloop mode, with the IBC amplitude and phase manually input by the operator. The rotor was automatically re-trimmed with each IBC input in order to ensure the rotor was operating at the same conditions with and without IBC excitation. Details on this automatic trim control method can be found in Ref. 18.

Test data were averaged over 128 rotor revolutions and each data set was sampled at a rate of 256 samples/rev (about $1.4^{\circ}$ resolution).

\section{Description of Analytical Methods}

The analytical results were obtained using the comprehensive analysis CAMRAD II and coupled CAMRAD II/OVERFLOW 2. A description of each method is provided in this section. 


\section{CAMRAD II}

CAMRAD II is an aeromechanics analysis of rotorcraft that incorporates a combination of advanced technologies, including multibody dynamics, nonlinear finite elements, and rotorcraft aerodynamics [19]. CAMRAD II has been used extensively for correlation of performance and loads measurements of the UH-60A in various flight conditions [20-23].

The aerodynamic model is based on second-order lifting line theory [24]. The blade section aerodynamic modeling in lifting line theory is unsteady, compressible, viscous flow about an infinite wing in a uniform flow consisting of a yawed freestream and wake-induced velocity. This problem is modeled within CAMRAD II as two-dimensional, steady, compressible, viscous flow (airfoil tables), plus corrections for swept and yawed flow, spanwise drag, unsteady loads, and dynamic stall. The wake modeling of lifting line theory is an incompressible vortex wake behind the lifting line, with distorted geometry and rollup. The wake analysis calculates the rotor nonuniform induced velocity. The tip vortex formation is modeled.

In this work, an isolated rotor is modeled as a flexible blade with nonlinear finite elements. A dual-peak free wake model is used for rotor analysis.

\section{OVERFLOW 2}

All Navier-Stokes CFD analysis presented herein was performed using OVERFLOW 2 version 2.1aa [25]. OVERFLOW 2 is an overset, structured-mesh flow solver developed at NASA. For two decades the OVERFLOW solver has served to analyze a variety of rotorcraft under a wide range of flight conditions [26].

OVERFLOW 2 offers a wide variety of numerical schemes, turbulence models, and boundary conditions. For the present study, OVERFLOW 2 was run with 2 nd order central differencing and 4th order artificial dissipation in space. Time marching was performed using a 2 nd order dual timestepping scheme. Turbulence was modeled near blade surfaces using the Spalart-Almaras one-equation model. The turbulence model was deactivated in regions one-chord length or further from the rotor blades. Blade surfaces were modeled as viscous, adiabatic walls; outer boundaries were modeled using a characteristic condition imposing freestream quantities.

OVERFLOW 2 computes the flowfield by discretizing the Navier-Stokes equations on a series of overset, structured grids. Grids modeling the rotor blades were body-fitted and curvilinear. These grids, often called near-body grids, extended approximately one-chord length from the blade surface. The near-body grids were nested in a series of Cartesian grids, called off-body grids, which filled the space between the rotor and the farfield boundary located 5 rotor radii from the hub. The OVERFLOW 2 model did not include a hub, the LRTA, the wind tunnel struts, or the wind tunnel walls. All grids exchanged flow information in regions of overlap at their faces. This grid system is illustrated in Fig. 3. The model contained 4.5 million points, 1.9 million points in the near-body and 2.6 million in the off-body.

The near-body grid representing the bulk of each rotor blade had a $\mathrm{C}-\mathrm{H}$ topology with 125 points wrapping around the blade chordwise, 82 points along the blade span, and 33 points normal to the surface. The initial spacing at the blade surface had a $y^{+}$value of 2 . The finest off-body grid had a spacing of 0.2 tip-chord lengths in all three directions. By most measures this is a very coarse grid system. However, experience has shown that this coarse grid system yields more accurate performance prediction than finer grid systems for this geometry. Furthermore, the high advance ratios investigated here reduce the need for accurate wake capture. Finally, the reduced computational effort permits the simulation of a larger number of flight conditions.

OVERFLOW 2 required approximately 12 minutes to advance the solution 1/4 rotor revolution using this configuration and 64 CPUs on an SGI Altix ICE computer.

\section{Coupled Analysis of CAMRAD II/OVERFLOW 2}

CAMRAD II uses a lower-fidelity aerodynamics model than that available in modern CFD codes, and most CFD codes lack the sophisticated Computational Structural Dynamics (CSD) and trim capabilities of comprehensive codes like CAMRAD II. Coupling a CFD code (e.g. OVERFLOW 2) to a comprehensive code (e.g. CAMRAD II) marries the strengths of the two approaches and produces the highestfidelity solution currently possible.

For this study, coupling is achieved by alternate execution of OVERFLOW 2 and CAMRAD II. At the end of each code's turn to execute, it passes data to the next code. The data passed from OVERFLOW 2 to CAMRAD II is airload data integrated from its Navier-Stokes model of the UH-60 rotor. This airload data is used to replace CAMRAD II's internal aerodynamics model (which consists of airfoil tables and a lower-order wake model). At the end of its execution, CAMRAD II generates updated control positions and a description of how the blade deforms as it revolves around the shaft. These quantities are used to give OVERFLOW 2's grids a realistic motion in response to the aerodynamic environment. This algorithm, called the delta coupling technique, was pioneered by Tung et al. [27] and implemented in OVERFLOW 2 by Nygaard et al. [28]. Significantly improved airloads prediction capability was demonstrated for the UH-60A rotor (without IBC) using a loosely coupled CAMRAD II/OVERFLOW-D in steady level flight conditions by Potsdam et al. [11]. 
Inputs for uncoupled CAMRAD II runs were identical to inputs used for coupled CAMRAD II runs with a single exception. For coupled calculations, the CAMRAD II wake model was switched from a free wake model to uniform inflow. The choice of CAMRAD II wake model has no impact on the accuracy of the resulting simulation because the coupling algorithm is designed to replace the wake model with a full CFD simulation. Selecting uniform inflow as the CAMRAD II wake model speeds calculations and prevents crosstalk between the CAMRAD II wake model and the CFD analysis from destabilizing the coupling process.

Convergence of the coupling process was determined by monitoring blade airloads for periodicity. When the airloads did not vary significantly from one coupling iteration to the next, the solution was judged to be converged. For the present analysis, this generally occurred after 24 coupling iterations. Since OVERFLOW 2 was allowed to iterate for $1 / 4$ revolution between coupling exchanges, this equates to 6 full revolutions for the converged solution. A fully converged coupled solution required approximately 5.5 hours to compute on 64 SGI Altix ICE processors.

A sample result for the coupled analysis at $\mu=0.40$ is visualized in Fig. 4. The blade surfaces are colored by pressure coefficient and the wake is depicted by an iso-surface of q-criterion. Detailed airloads will be shown in a later section.

\section{Trim Conditions for Analysis}

The trim parameters used in the predictions were the same as those from the test, including non-dimensional rotor lift, propulsive force, and hub rolling moment. In addition, hover tip Mach number, advance ratio, shaft angle of attack, and IBC displacement (magnitude and phase) were specified. A wind tunnel wall correction, in the form of an induced angle correction, was used to correct the measured rotor lift, propulsive force, and shaft angle [29]. The test conditions shown in Table 1 are corrected values.

\section{Results and Discussion}

In this section, selected data from the wind tunnel test are presented and then compared with predictions from the two analysis methods. These test data include rotor performance, IBC actuator force, blade bending moments, and vibratory hub loads both with and without $2 /$ rev IBC inputs. The test conditions evaluated were those that demonstrated the greatest benefit of $2 / \mathrm{rev}$ IBC for performance improvement and include data at various IBC amplitudes and phase angles.

\section{Rotor Performance}

Figure 5 shows the effects of $2 / \mathrm{rev}$ IBC on main rotor power at the advance ratios of 0.35 and 0.40 . IBC amplitudes were $1.5^{\circ}$ at $\mu=0.35$ and $1.0^{\circ}, 1.5^{\circ}, 2.0^{\circ}, 2.5^{\circ}$ at $\mu=0.40$. IBC phase angles varied from $150^{\circ}$ to $300^{\circ}$ at $15^{\circ}$ intervals. The measured rotor power with IBC is compared with the baseline (no IBC) values. The test conditions and trim targets are summarized in Table 1 . Rolling moment $\left(C_{m x} / \sigma\right)$ is positive starboard down and rotor shaft angle $\left(\alpha_{s}\right)$ is positive aft tilt. It should be noted that the propulsive force at $\mu=0.4$ is smaller than that at $\mu=0.35$ because of control limitations.

In general, the measured data show smooth trends. Each plot has the same vertical range $(0.002)$ so that the relative variations can be easily compared. The data show that the $2 /$ rev IBC actuation reduces main rotor power with proper phases and the power reduction increases as airspeed increases. Optimum phase was $225^{\circ}$ at both advance ratios. The largest power reduction was obtained with both $1.5^{\circ}$ and $2.0^{\circ}$ IBC amplitudes at $\mu=0.40$.

$\begin{array}{lccrr}\text { Main } & \text { rotor power } & \text { variations } & \text { were } & \text { calculated } \\ \text { with } & \text { CAMRAD II } & \text { alone } & \text { and } & \text { coupled }\end{array}$ CAMRAD II/OVERFLOW 2 and the results were compared with the measured values (Figs. 6 and 7). The phase angles used for the CAMRAD II analysis were varied from $0^{\circ}$ to $330^{\circ}$ at an interval of $30^{\circ}$. For the coupled analysis, only five IBC phase angles $\left(150^{\circ}, 195^{\circ}, 225^{\circ}, 255^{\circ}\right.$, and $\left.300^{\circ}\right)$ were are used to reduce computational cost.

Figure 6 compares the calculated main rotor power and its variations with respect to baseline (no IBC) with the measured values at $\mu=0.35$. There is a substantial difference between the calculations and measurements in terms of absolute power as shown in Fig. 6(a). CAMRAD II underpredicted the baseline power by 3\% and CAMRAD II/OVERFLOW 2 overpredicted it by $8 \%$.

The calculated main rotor power variation in terms of $\%$ change from the baseline is compared with the measured values in Fig. 6(b). The calculated variations are referred to each method's respective baseline (no IBC) values. The test data show that the power reduction is as much as $3.4 \%$ with the IBC phase of $225^{\circ}$. This is equivalent to $5.8 \%$ increase in rotor lift to effective-drag ratio. CAMRAD II shows reasonably good correlation with the measured variation of data in magnitude. However, the curve is shifted to the left compared to the data. CAMRAD II/OVERFLOW 2 shows excellent correlation in terms of both the magnitude and phase of the variation. The calculated maximum power reductions are $2.7 \%$ with the IBC phase of $210^{\circ}$ for CAMRAD II and $3.6 \%$ with the IBC phase of $225^{\circ}$ for CAMRAD II/OVERFLOW 2.

Figure 7 compares the calculated main rotor power variation with the measured values at $\mu=0.40$. IBC amplitudes are $1.0^{\circ}$, $1.5^{\circ}, 2.0^{\circ}$, and $2.5^{\circ}$. The test data are the same as those shown in Fig. 5(b), except that the power variations are plotted. The test data show that the $1.0^{\circ} \mathrm{IBC}$ actuation reduces main rotor power up to $2.9 \%$ with the IBC phase of $240^{\circ}, 1.5^{\circ} \mathrm{IBC}$ actuation up to $5.1 \%, 2.0^{\circ}$ IBC up to $5.1 \%$, and $2.5^{\circ}$ IBC up 
to $4.4 \%$ with the IBC phase of $225^{\circ}$. These are equivalent to $4.7 \%, 8.6 \%, 8.6 \%$, and $8.0 \%$ increase in rotor lift to effectivedrag ratio. Again, the calculated variations are referred to each method's respective baseline (no IBC) values. In terms of absolute power, CAMRAD II underpredicted the baseline power by $8 \%$ and CAMRAD II/OVERFLOW 2 overpredicted it by $4 \%$. CAMRAD II shows worse correlation than at $\mu=0.35$ and significantly underpredicts the benefit of IBC in rotor power reduction. The calculated maximum power reduction of $2.3 \%$ occurs with $1.5^{\circ}$ IBC actuation at $210^{\circ}$ IBC phase. Again the curve is shifted to the left compared to the data. CAMRAD II/OVERFLOW 2 shows excellent correlation in terms of both the magnitude and phase of the variation. The maximum power reduction predicted by the coupled analysis are $3.5 \%, 4.5 \%, 5.1 \%$, and $5.4 \%$ with IBC amplitudes of $1.0^{\circ}, 1.5^{\circ}, 2.0^{\circ}$, and $2.5^{\circ}$.

In order to better understand the physical mechanism behind the rotor performance gains due to $2 /$ rev IBC, as well as the difference between CAMRAD II and coupled CAMRAD II/OVERFLOW 2 predictions, rotor aerodynamics calculated with the two analyses are examined.

Figure 8 shows the calculated rotor blade sectional normal force, torque, and pitching moment with CAMRAD II/OVERFLOW 2 at $\mu=0.40$. The top row shows the baseline (no IBC) results, the second row shows the results obtained with the optimum IBC input $\left(2^{\circ}\right.$ amplitude and $225^{\circ}$ phase), and the third row shows the difference between the two results. At this high speed flight condition, the airloads in the blade tip region are characterized by negative lift at the end of the first quadrant and the beginning of the second quadrant. This negative lift is eliminated by the $2 / \mathrm{rev}$ IBC actuation with an increased blade pitch angle generated by the IBC with $225^{\circ}$ phase $(2 / \mathrm{rev}$ IBC with $225^{\circ}$ phase generates blade pitch motions that have positive peaks at azimuth angles of $112.5^{\circ}$ and $292.5^{\circ}$ and negative peaks at azimuth angles of $22.5^{\circ}$ and $202.5^{\circ}$ ). This pitch angle increase also increases blade pitching moment. A small increase in lift is also observed in the fourth quadrant, again near the blade tip region. Reduction of lift is observed in the first quadrant and the front of the rotor disk to maintain constant lift. Blade sectional torque shows $2 / \mathrm{rev}$ variations closely matching the IBC input. Torque reductions are observed in the first and third quadrants and torque increase is observed in the fourth quadrant. In the second quadrant, torque is reduced near the blade tip, but increased on the inboard part of the blade. Overall, torque is reduced.

Figure 9 shows the calculated rotor blade sectional normal force, torque, and pitching moment with CAMRAD II at $\mu=0.40$. The baseline (no IBC) results show the same general trends as the coupled results, but the magnitudes of negative lift and pitching moment are smaller. The delta lift shows similar magnitude and trend to the coupled results. The delta torque and pitching moment show similar trends to the coupled results. However, the magnitudes are substantially reduced. Note that the range of $\Delta \mathrm{C}_{\mathrm{q}} / \sigma$ is $1 / 5$ the delta for the coupled analysis, although all the other quantities are plotted to the same ranges as the coupled results. The smaller delta pitching moment predicted by CAMRAD II creates smaller elastic twist of the blade, and thus smaller delta power compared to the coupled analysis.

\section{IBC actuator and blade loads}

In this section, IBC actuator force (pitch link force), flap bending moment, and chord bending moment are examined for the $2 /$ rev IBC conditions evaluated above.

Figure 10(a) compares the measured IBC actuator force at various IBC phases with the baseline (no IBC) values at $\mu=0.35$. Steady values are removed from the test data so that only oscillatory components are compared. There are significant variations of IBC actuator force as IBC phase varies, especially in the second quadrant.

The calculated peak-to-peak IBC actuator force variations are compared with the measured values in Fig. 10(b). Test data show a maximum $24.0 \%$ reduction of IBC actuator force with $210^{\circ}$ IBC phase. At the optimum phase of $225^{\circ}$ for rotor performance, the peak-to-peak IBC actuator force is reduced by $21.6 \%$. The calculated IBC actuator force reductions are $27.4 \%$ with the IBC phase of $210^{\circ}$ for CAMRAD II and $33.9 \%$ with the IBC phase of $195^{\circ}$ for the coupled analysis. Although the maximum reduction of IBC actuator force is better predicted with CAMRAD II, general trends are better captured with the coupled analysis.

Figure 11 compares the measured IBC actuator force with the various IBC phases for the four different values of IBC amplitudes at $\mu=0.40$. The trends are very similar to the $\mu=0.35$ results. There are larger variations in amplitude as the IBC amplitude increases.

The calculated peak-to-peak IBC actuator force variations are compared with the measured values in Fig. 12. Test data show a maximum $17.7 \%$ reduction of IBC actuator force with $255^{\circ}$ IBC phase for $1.0^{\circ}$ IBC amplitude. The maximum reduction of IBC actuator force decreases as IBC amplitude increases and the phase for the maximum reduction decreases as well. At the optimum phase for rotor performance, IBC actuator force is reduced by $11.3 \%$ to $15.7 \%$ for the IBC amplitudes tested.

The CAMRAD II calculated IBC actuator force reductions are from $15.4 \%$ with the IBC amplitude of $1.0^{\circ}$ to $27.3 \%$ with the IBC amplitude of $2.5^{\circ}$. The reductions of IBC actuator force predicted by CAMRAD II begin at substantially earlier phase angles for all the IBC amplitudes examined. The CAMRAD II/OVERFLOW 2 calculated IBC actuator force reductions are $25.0 \%$ with the IBC amplitude of $1.0^{\circ}$ to $37.8 \%$ with the IBC amplitude of $2.5^{\circ}$. Again, the maximum 
reduction of IBC actuator force is better predicted with CAMRAD II, but general trends are better captured with the coupled analysis.

Figure 13 compares the measured flap bending moments at $30 \% \mathrm{R}$ with the various IBC phases for two different IBC amplitudes $\left(1.0^{\circ}\right.$ and $\left.1.5^{\circ}\right)$ at $\mu=0.4$. Due to an instrumentation problem, data were not available at higher IBC amplitudes. In general, the variation is very small. However, the minimum peak around azimuth of $170^{\circ}$ increases and maximum peak around azimuth of $270^{\circ}$ decreases at the same time, and thus the peak-to-peak variations are about $10 \%$ for the $1.0^{\circ}$ and $18 \%$ for the $1.5^{\circ}$ IBC amplitude as shown in Fig. 14. At the optimum phase for rotor performance, the peak-to-peak flap bending moment decreases by $5.1 \%$ and $5.4 \%$ for the IBC amplitudes of $1.0^{\circ}$ and $1.5^{\circ}$, respectively. Both CAMRAD II and CAMRAD II/OVERFLOW 2 are unable to capture either magnitude or trend.

Figure 15 compares the measured chord bending moments at $40 \% \mathrm{R}$ with the various IBC phases for two different IBC amplitudes at $\mu=0.4$. In general, the variation is small and the only noticeable variation occurs around azimuth $225^{\circ}$. The peak-to-peak magnitude of chord bending moment decreases for the IBC phases investigated as shown in Fig. 16. At the optimum phase for rotor performance, however, the peakto-peak chord bending moment increases by $0.3 \%$ and $1.3 \%$ for the IBC amplitudes of $1.0^{\circ}$ and $1.5^{\circ}$, respectively. The coupled analysis shows reasonably good correlation up to the IBC phase of $225^{\circ}$, however, it is not able to capture the downward trends after that.

\section{Vibratory Hub Loads}

Figure 17 shows the measured 4/rev hub load variation with IBC phase for $\mu=0.4$. $2 / \mathrm{rev}$ IBC has a significant influence on vibratory hub loads. More than $90 \%$ reduction of $4 / \mathrm{rev}$ hub normal force with $1.5^{\circ} \mathrm{IBC}$ amplitude and $300^{\circ} \mathrm{IBC}$ phase is noteworthy. $4 / \mathrm{rev}$ hub normal force $\left(\mathrm{F}_{\mathrm{Z}}\right)$, axial force $\left(\mathrm{F}_{\mathrm{X}}\right)$, and pitching moment $\left(\mathrm{M}_{\mathrm{y}}\right)$ decrease as the IBC phase increases, while $4 / \mathrm{rev}$ hub side force $\left(\mathrm{F}_{\mathrm{y}}\right)$ and rolling moments $\left(\mathrm{M}_{\mathrm{X}}\right)$ increase as the IBC phase increases. The same trends are observed with different IBC amplitudes. At the optimum phase of $225^{\circ}$ for rotor performance, vibratory hub normal force decreases by $27.3 \%$, hub axial force by $26.5 \%$, and hub pitching moment by $16.2 \%$. However, vibratory hub side force increases by $29.2 \%$ and hub rolling moment by $36.3 \%$.

Figure 18 compares the calculated vibratory hub load variations with the measured values for $\mu=0.4$ and IBC amplitude of $1.5^{\circ}$. The correlation of vibratory hub loads is generally poor by both methods, although the coupled analysis somewhat captures general trends.

\section{Summary of Correlation}

The effects of $2 / \mathrm{rev}$ IBC on measured and predicted rotor performance, IBC actuator force, blade bending moments, and vibratory hub loads at optimum phase are compared in Table 2. The changes are expressed in terms of the percentage variations from the baseline (no IBC) results.

\section{Conclusions}

Wind tunnel measurements of the performance, loads, and vibration of a full-scale UH-60A Black Hawk main rotor with an individual blade control (IBC) system are compared with calculations obtained using the comprehensive helicopter analysis CAMRAD II and coupled CAMRAD II/OVERFLOW 2 analysis. In particular, comparisons are made for a range of $2 / \mathrm{rev}$ IBC input amplitudes and phases at two advance ratios.

From this study the following conclusions were obtained:

1) Measured data show a $5.1 \%$ rotor power reduction $(8.6 \%$ rotor lift to effective-drag ratio increase) using $2 /$ rev IBC actuation with $2.0^{\circ}$ amplitude at $\mu=0.4$. At the optimum IBC phase for rotor performance, IBC actuator force (pitch link force) also decreased, and both flap and chord bending moments remained unchanged. Vibratory hub loads were significantly affected.

2) CAMRAD II predicts the rotor power variations with IBC phase reasonably well at $\mu=0.35$. However, the correlation degrades at $\mu=0.4$. The benefit of IBC in rotor performance is substantially underpredicted.

3) Coupled CAMRAD II/OVERFLOW 2 shows excellent correlation with the measured rotor power variations with IBC phase at both $\mu=0.35$ and $\mu=0.4$. Both maximum power reduction and optimum phase are accurately predicted.

4) $2 /$ rev IBC inputs with optimum phase increases blade section lift at the end of the first quadrant and the beginning of the second quadrant by eliminating negative lift near the blade tip, and decreases lift in the first quadrant and the front of the rotor disk. Blade sectional torque shows $2 / \mathrm{rev}$ variations, closely matching the IBC input. Torque reductions are observed in the first and third quadrants and torque increase is observed in the fourth quadrant. In the second quadrant, torque is reduced near the blade tip, but increased on the inboard part of the blade. Overall, torque is reduced.

5) Measured data show that $2 /$ rev IBC inputs reduce IBC actuator force (pitch link force) by $24 \%$ at $\mu=0.35$ and up to $17.7 \%$ at $\mu=0.40$. The IBC inputs for optimum rotor performance also reduce IBC actuator force. The analyses show that the maximum reduction of IBC actuator force is better predicted with CAMRAD II, but general trends are better captured with the coupled analysis. 
6) Measured flap and chord bending moments show about 10 to $15 \%$ reductions in peak-to-peak magnitude for the IBC phases investigated. At the optimum IBC phase for rotor performance, neither flap nor chord bending moments changed significantly. Both CAMRAD II and CAMRAD II/OVERFLOW 2 are unable to capture peakto-peak flap bending moment variations in terms of both magnitude and trends. The coupled analysis shows reasonably good correlation of chord bending moment variations up to the IBC phase of $225^{\circ}$.

7) Measured data show that $2 / \mathrm{rev}$ IBC has a significant influence on vibratory hub loads. 4/rev hub normal force, axial force, and pitching moment decrease as the IBC phase increases for the IBC phases investigated and 4/rev hub side force and rolling moments increase as the IBC phase increases. The correlation of vibratory hub loads is generally poor by both methods, although the coupled analysis somewhat captures general trends.

\section{Acknowledgment}

The authors gratefully acknowledge the significant efforts of the project partners (NASA, U.S. Army, ZFL, and Sikorsky) as well as the U.S. Air Force, in the planning, preparation, and execution of the IBC test.

\section{References}

[1] Norman, T. R., Theodore, C., Shinoda, P. M., Fuerst, D., Arnold, U. T. P., Makinen, S., Lorber, P., and O'Neill, J., "Full-scale Wind Tunnel Test of a UH-60 Individual Blade Control System for Performance Improvement and Vibration, Loads, and Noise Control," American Helicopter Society 65th Annual Forum Proceedings, Grapevine, TX, May 27-29, 2009.

[2] Norman, T. R., Shinoda, P. M., Kitaplioglu, C., Jacklin, S. A., and Sheikman, A., "Low-Speed Wind Tunnel Investigation of a Full-Scale UH-60 Rotor System," American Helicopter Society 58th Annual Forum Proceedings, Montreal, Canada, June 11-13, 2002.

[3] Richter, P., Eisbrecher, H. D., and Klöppel, V., “Design and First Flight Test of Individual Blade Control Actuators," 16th European Rotorcraft Forum, Glasgow, Scotland, September 18-20, 1990.

[4] Teves, D., Klöppel, V., and Richter, P., "Development of Active Control Technology in the Rotating System, Flight Testing and Theoretical Investigations," 18th European Rotorcraft Forum, Avignon, France, September 15-18, 1992.
[5] Jacklin, S. A., Blaas, A., Teves, D., and Kube, R., "Reduction of Helicopter BVI Noise, Vibration, and Power Consumption through Individual Blade Control," American Helicopter Society 51st Annual Forum Proceedings, Fort Worth, TX, May 9-11, 1995.

[6] Jacklin, S. A., Blaas, A., Swanson, S. M., and Teves, D., "Second Test of a Helicopter Individual Blade Control System in the NASA Ames 40- by 80-Foot Wind Tunnel,' American Helicopter Society 2nd International Aeromechanics Specialists' Conference, Bridgeport, CT, October 11-13, 1995.

[7] Arnold, U. T. P., "Recent IBC Flight Test Results from the CH-53G Helicopter," 29th European Rotorcraft Forum, Friedrichshafen, Germany, September 16-18, 2003.

[8] Arnold, U. T. P., Müller, M., and Richter, P., "Theoretical and Experimental Prediction of Individual Blade Control Benefits," 23rd European Rotorcraft Forum, Dresden, Germany, September 16-18, 1997.

[9] Cheng, R. P., and Celi, R., "Optimum Two-PerRevolution Inputs for Improved Rotor Performance," Journal of Aircraft, Vol. 42, No. 6, November-December 2005, pp. 1409-1417.

[10] Yeo, H., "Assessment of Active Controls for Rotor Performance Enhancement," Journal of the American Helicopter Society, Vol. 53, (2), April 2008, pp. 152163.

[11] Potsdam, M., Yeo, H., and Johnson, W., "Rotor Airloads Prediction Using Loose Aerodynamic/Structural Coupling," Journal of Aircraft, Vol. 43, No. 3, MayJune 2006.

[12] Bhagwat, M. J., Ormiston, R. A, Saberi, H. A., and Xin, H., "Application of CFD/CSD Coupling for Analysis of Rotorcraft Airloads and Blade Loads in Maneuvering Flight," American Helicopter Society 63rd Annual Forum Proceedings, Virginia Beach, VA, May 13, 2007.

[13] Jain, R., Szema, K., Munipalli, R., Yeo, H., and Chopra, I., "CFD-CSD Analysis of Active Control of Helicopter Rotor for Performance Improvement," American Helicopter Society 65th Annual Forum, Grapevine, Texas, May 27-29, 2009.

[14] Jain, R., Yeo, H., and Chopra, I., "An Examination of Rotor Loads due to On-Blade Active Controls for Performance Enhancement using CFD/CSD Analysis," AHS Specialists' Conference on Aeromechanics, San Francisco, CA, January 20-22, 2010. 
[15] Dietz, M., Krämer, E., Wagner, S., and Altmikus, A., "Active Rotor Performance Investigations Using CFD/CSD Weak Coupling," 33rd European Rotorcraft Forum, Kazan, Russia, September 11-13, 2007.

[16] Ananthan, S., and Baeder, J. D., "Prediction and Validation of Loads on Bearingless Rotors Using a Coupled CFD-CSD Methodology," American Helicopter Society 64th Annual Forum Proceedings, Montreal, Canada, April 29-May 1, 2008.

[17] Haber, A., Jacklin, S. A., and deSimone, G., "Development, Manufacturing, and Component Testing of an Individual Blade Control System for a UH60 Helicopter Rotor," American Helicopter Society Aerodynamics, Acoustics, and Test and Evaluation Technical Specialists Meeting, San Francisco, CA, January 23-25, 2002.

[18] Theodore, C. and Tischler, M., "Development and Operation of an Automatic Rotor Trim Control System for the UH-60 Individual Blade Control (IBC) Wind Tunnel Test,' AHS Specialists' Conference on Aeromechanics, San Francisco, CA, January 20-22, 2010 .

[19] Johnson, W., "Technology Drivers in the Development of CAMRAD II," American Helicopter Society Aeromechanics Specialist Meeting, San Francisco, CA, January 19-21, 1994.

[20] Yeo, H., Bousman, W. G., and Johnson, W., "Performance Analysis of a Utility Helicopter with Standard and Advanced Rotor,' Journal of the American Helicopter Society, Vol. 49, No. 3, July 2004, pp. 250270.

[21] Shinoda, P. M., Yeo. H., and Norman, T. R., "Rotor Performance of a UH-60 Rotor System in the NASA Ames 80 - by 120-Foot Wind Tunnel," Journal of the American Helicopter Society, Vol. 49, No. 4, October 2004.

[22] Yeo, H., and Johnson, W., "Assessment of Comprehensive Analysis Calculation of Airloads on Helicopter Rotors," Journal of Aircraft, Vol. 42, No. 5, September-October 2005.

[23] Yeo, H., and Johnson, W., "Prediction of Rotor Structural Loads with Comprehensive Analysis," Journal of the American Helicopter Society, Vol. 53, No. 2, April 2008.

[24] Johnson, W., "Recent Developments in Rotary-Wing Aerodynamic Theory," AIAA Journal, Vol. 24, No. 8, 1986, pp. 1219-1244.
[25] Buning, P. G., Gomez, R. J., and Scallion, W. I., "CFD Approaches for Simulation of Wing-Body Stage Separation," AIAA-2004-4838, AIAA 22nd Applied Aerodynamics Conference, Providence, RI, August 1619, 2004.

[26] Potsdam, M., Strawn, R. C., and Meakin, R., "Dynamic Rotorcraft Applications Using Overset Grids," 31st European Rotorcraft Forum, Florence, Italy, September $13-15,2005$

[27] Tung, C., Caradonna, F. X., and Johnson, W., "The Prediction of Transonic Flows on an Advancing Rotor," American Helicopter Society 40th Annual Forum, Arlington, VA, May 16-18, 1984

[28] Nygaard, T., Saberi, H., Ormiston, R. A., Strawn, R. C., and Potsdam, M., "CFD and CSD Coupling Algorithms and Fluid Structure Interface for Rotorcraft Aeromechanics in Steady and Transient Flight Conditions," American Helicopter Society 62nd Annual Forum, Phoenix, AZ, May 9-11, 2006

[29] Langer, H. -J., Peterson, R. L., and Maier, T. H., "An Experimental Evaluation of Wind Tunnel Wall Correction Methods for Helicopter Performance," American Helicopter Society 52nd Annual Forum, Washington, D.C., June 4-6, 1996. 
Table 1: Rotor trim and test conditions investigated.

\begin{tabular}{cccccc}
\hline \hline Run No. & $\mu$ & $C_{L} / \sigma$ & $C_{X} / \sigma$ & $C_{m x} / \sigma$ & $\alpha_{s}$ \\
\hline Run 99 & 0.35 & 0.077 & 0.0092 & -0.00092 & $-6.94^{\circ}$ \\
Run 117 & 0.40 & 0.077 & 0.0085 & -0.00131 & $-8.25^{\circ}$ \\
\hline
\end{tabular}

Table 2: Effects of 2/rev IBC on measured and calculated rotor performance, loads, and vibration at optimum phase.

\begin{tabular}{|c|c|c|c|c|c|}
\hline \multirow[b]{2}{*}{ IBC amplitude } & \multirow{2}{*}{$\begin{array}{r}\mu=0.35 \\
1.5^{\circ}\end{array}$} & \multicolumn{4}{|c|}{$\mu=0.40$} \\
\hline & & $1.0^{\circ}$ & $1.5^{\circ}$ & $2.0^{\circ}$ & $2.5^{\circ}$ \\
\hline \multicolumn{6}{|l|}{ Test } \\
\hline Optimum IBC phase for performance & $225^{\circ}$ & $240^{\circ}$ & $225^{\circ}$ & $225^{\circ}$ & $225^{\circ}$ \\
\hline Power change & $-3.4 \%$ & $-2.9 \%$ & $-5.1 \%$ & $-5.1 \%$ & $-4.4 \%$ \\
\hline Peak-to-peak IBC actuator force change & $-21.6 \%$ & $-15.7 \%$ & $-12.3 \%$ & $-12.5 \%$ & $-11.3 \%$ \\
\hline Peak-to-peak FBM @30\%R change & & $-5.1 \%$ & $-5.4 \%$ & & \\
\hline Peak-to-peak CBM @40\%R change & & $0.3 \%$ & $1.3 \%$ & & \\
\hline 4/rev hub normal force & & & $-27.3 \%$ & & \\
\hline 4/rev hub axial force & & & $-26.5 \%$ & & \\
\hline $4 /$ rev hub side force & & & $29.2 \%$ & & \\
\hline 4/rev hub rolling moment & & & $36.3 \%$ & & \\
\hline 4/rev hub pitching moment & & & $-16.2 \%$ & & \\
\hline \multicolumn{6}{|l|}{ CAMRAD II } \\
\hline Optimum IBC phase for performance & $210^{\circ}$ & $240^{\circ}$ & $210^{\circ}$ & $210^{\circ}$ & $210^{\circ}$ \\
\hline Power change & $-2.7 \%$ & $-2.0 \%$ & $-2.3 \%$ & $-1.9 \%$ & $-1.6 \%$ \\
\hline Peak-to-peak IBC actuator force change & $-27.4 \%$ & $-15.4 \%$ & $-19.6 \%$ & $-22.9 \%$ & $-20.8 \%$ \\
\hline Peak-to-peak FBM @30\%R change & & $3.1 \%$ & $2.1 \%$ & & \\
\hline Peak-to-peak CBM @40\%R change & & $-2.9 \%$ & $-6.9 \%$ & & \\
\hline 4/rev hub normal force & & & $18.8 \%$ & & \\
\hline 4/rev hub axial force & & & $9.2 \%$ & & \\
\hline $4 / \mathrm{rev}$ hub side force & & & $22.7 \%$ & & \\
\hline 4/rev hub rolling moment & & & $1.6 \%$ & & \\
\hline 4/rev hub pitching moment & & & $21.9 \%$ & & \\
\hline \multicolumn{6}{|l|}{ CAMRAD II/OVERFLOW 2} \\
\hline Optimum IBC phase for performance & $225^{\circ}$ & $225^{\circ}$ & $225^{\circ}$ & $225^{\circ}$ & $225^{\circ}$ \\
\hline Power change & $-3.6 \%$ & $-3.5 \%$ & $-4.5 \%$ & $-5.1 \%$ & $-5.4 \%$ \\
\hline Peak-to-peak IBC actuator force change & $-30.3 \%$ & $-25.0 \%$ & $-29.8 \%$ & $-38.4 \%$ & $-22.3 \%$ \\
\hline Peak-to-peak FBM @30\%R change & & $-14.1 \%$ & $-15.5 \%$ & & \\
\hline Peak-to-peak CBM @40\%R change & & $-5.0 \%$ & $-7.4 \%$ & & \\
\hline 4/rev hub normal force & & & $-31.5 \%$ & & \\
\hline 4/rev hub axial force & & & $-11.7 \%$ & & \\
\hline 4/rev hub side force & & & $-11.6 \%$ & & \\
\hline 4/rev hub rolling moment & & & $-7.4 \%$ & & \\
\hline 4/rev hub pitching moment & & & $22.8 \%$ & & \\
\hline
\end{tabular}




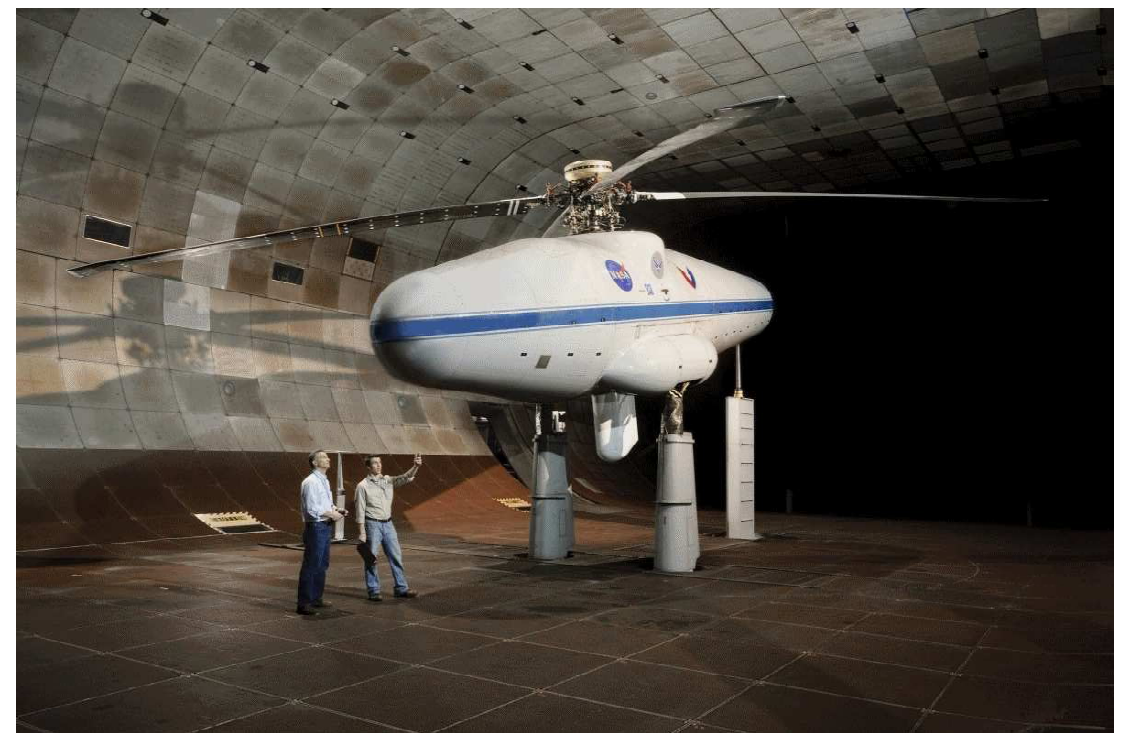

Fig. 1: UH-60A rotor system installed on the Large Rotor Test Apparatus in the NFAC 40-by 80-Foot Wind Tunnel.

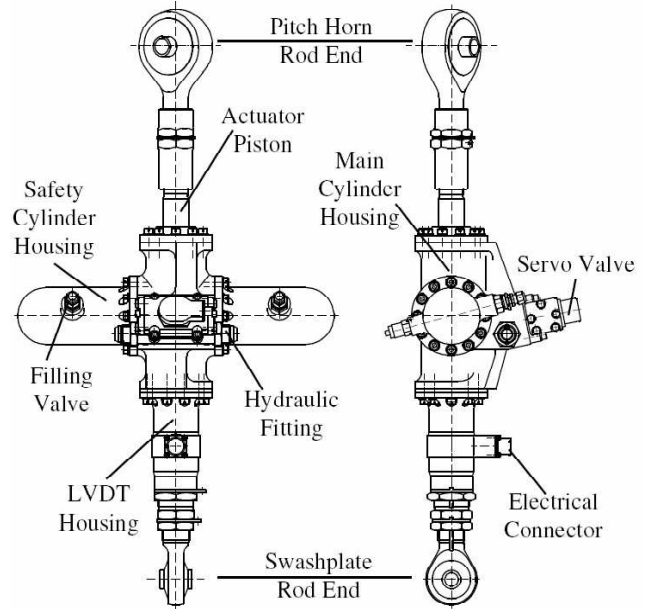

(a) IBC actuator schematic

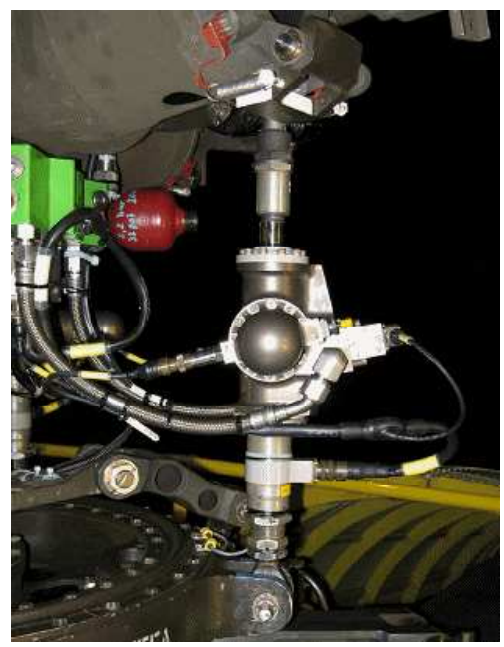

(b) IBC actuator installed on UH-60A rotor

Fig. 2: IBC actuator. 


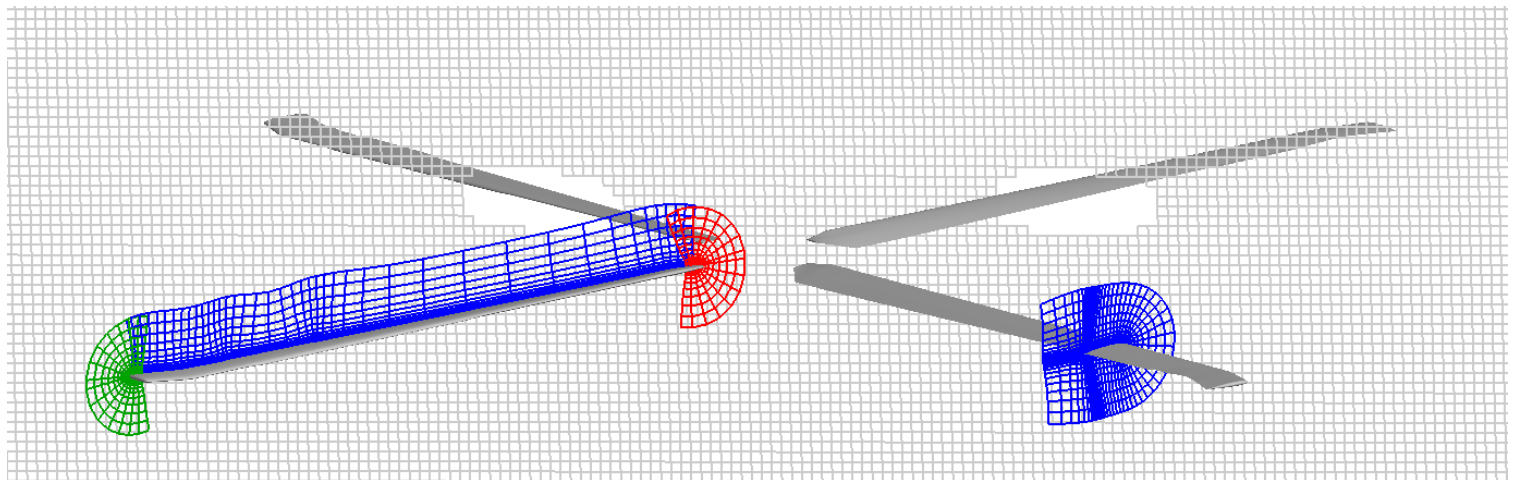

Fig. 3: Overset grid system for OVERFLOW 2 simulations. Every other point shown. Blade grid (blue), tip cap (green), root cap (red), off-body grids (gray).

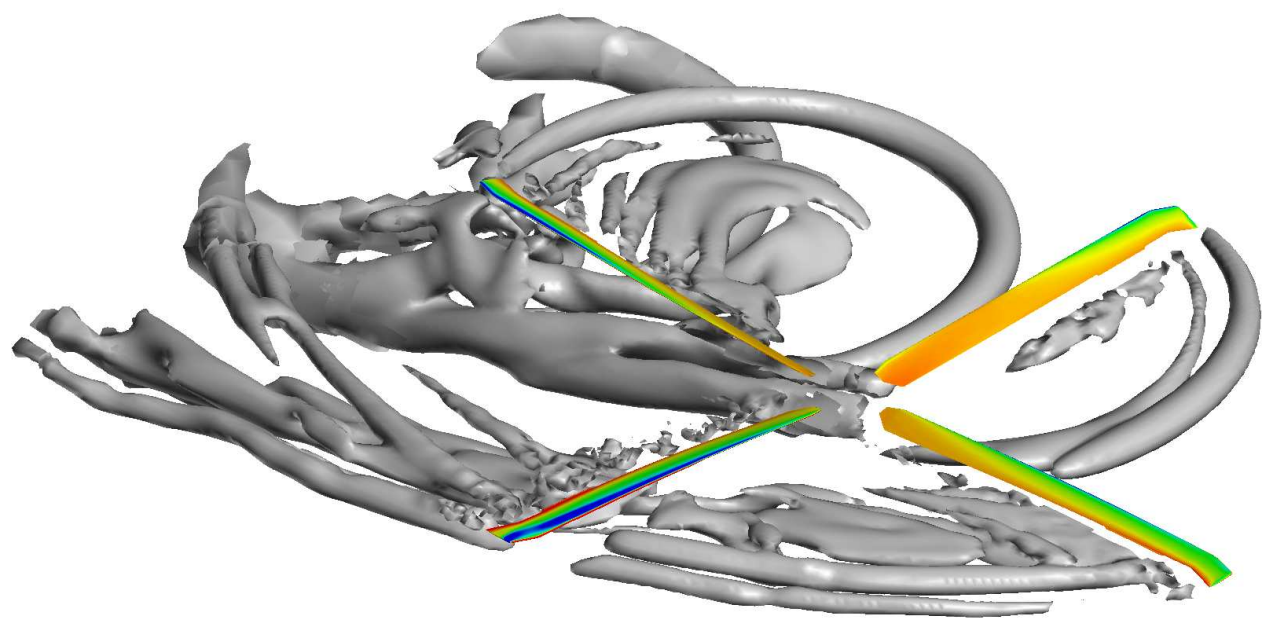

Fig. 4: Wake geometry and blade surface pressures, $\mu=0.40$. 


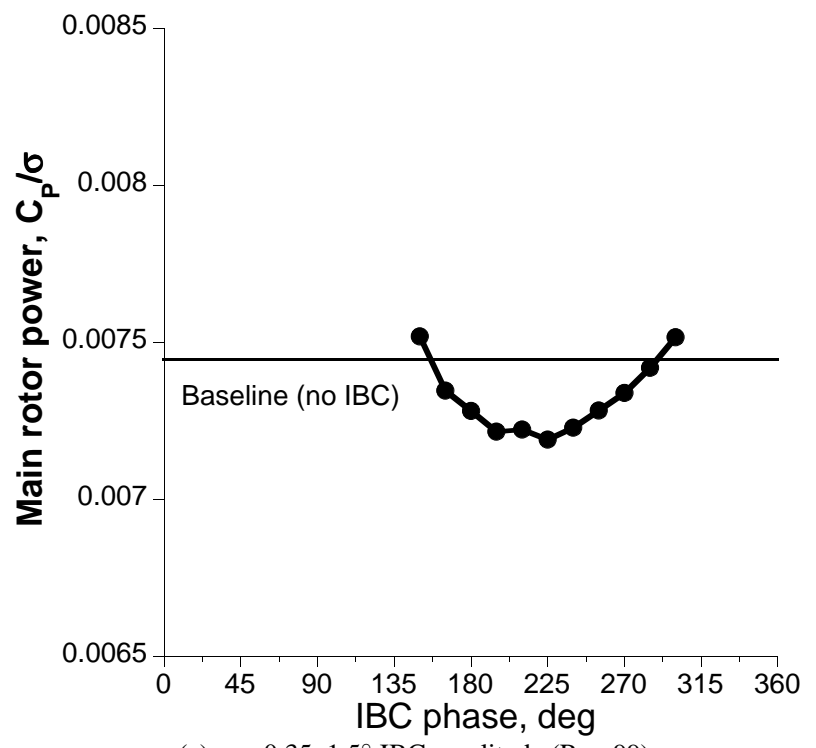

(a) $\mu=0.35,1.5^{\circ}$ IBC amplitude (Run 99)

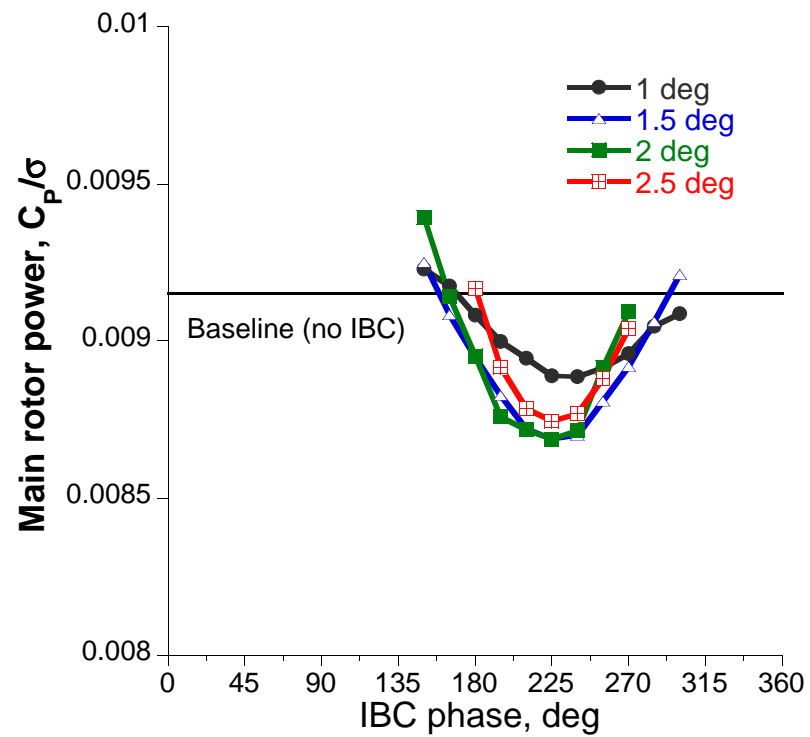

(b) $\mu=0.40$, IBC amplitude varies (Run 117)

Fig. 5: Measured main rotor power from 2/rev IBC phase sweep at two advance ratios. 

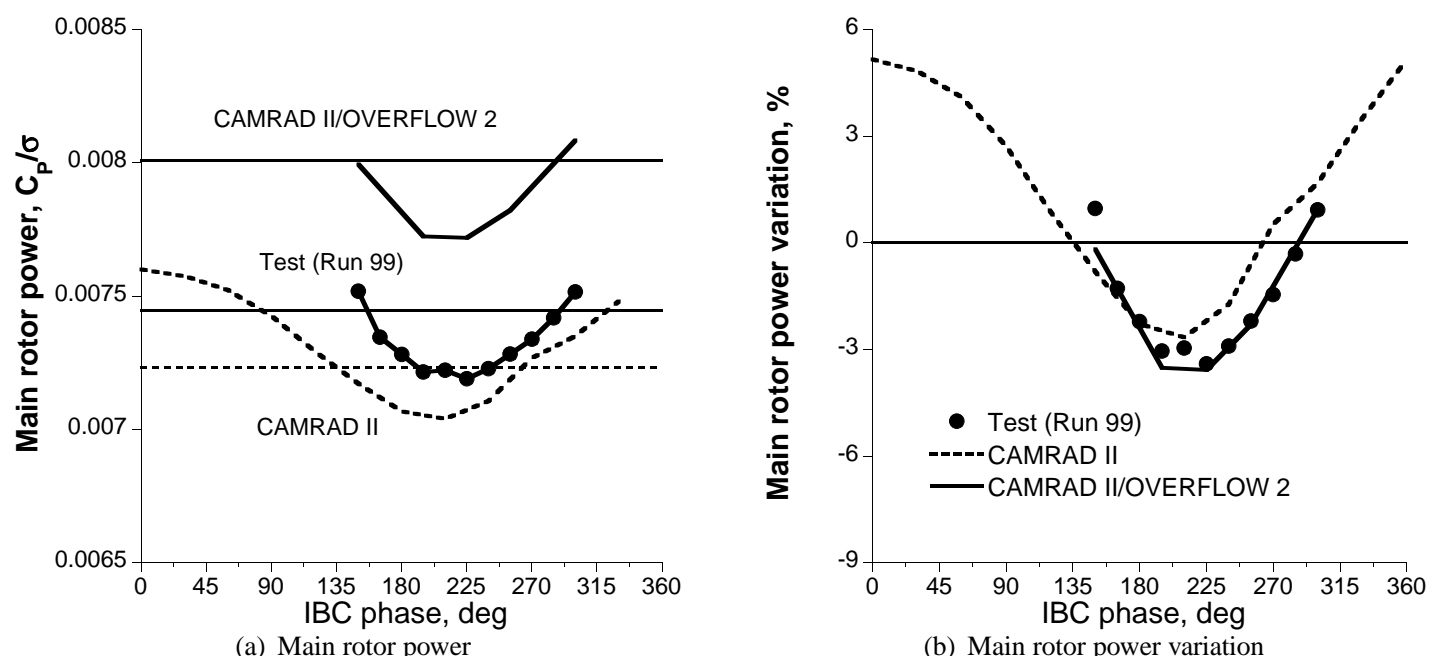

(a) Main rotor power

(b) Main rotor power variation

Fig. 6: Correlation of main rotor power and its variation from $2 / \mathrm{rev}$ IBC phase sweep ( $1.5^{\circ}$ amplitude $), \mu=0.35$.

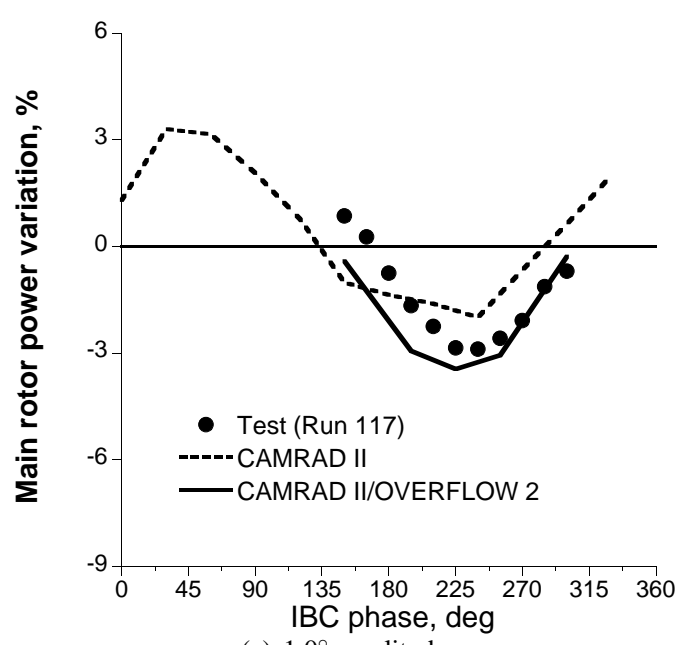

(a) $1.0^{\circ}$ amplitude

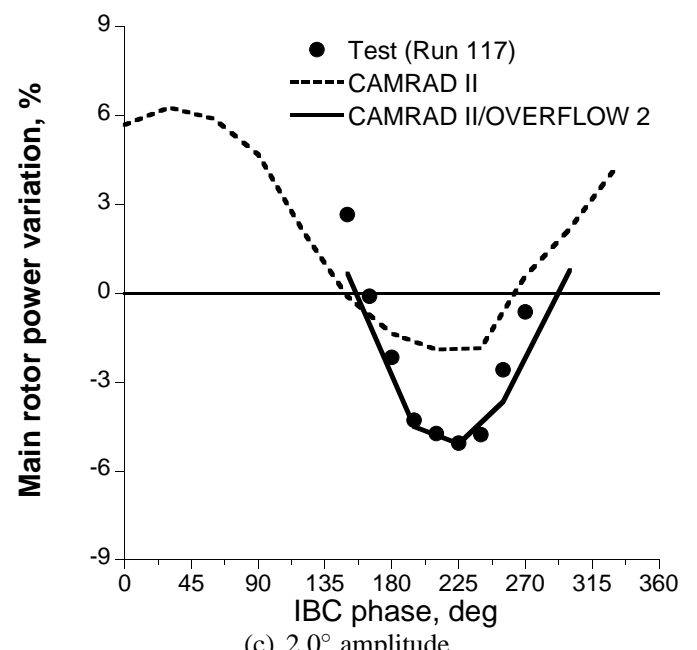

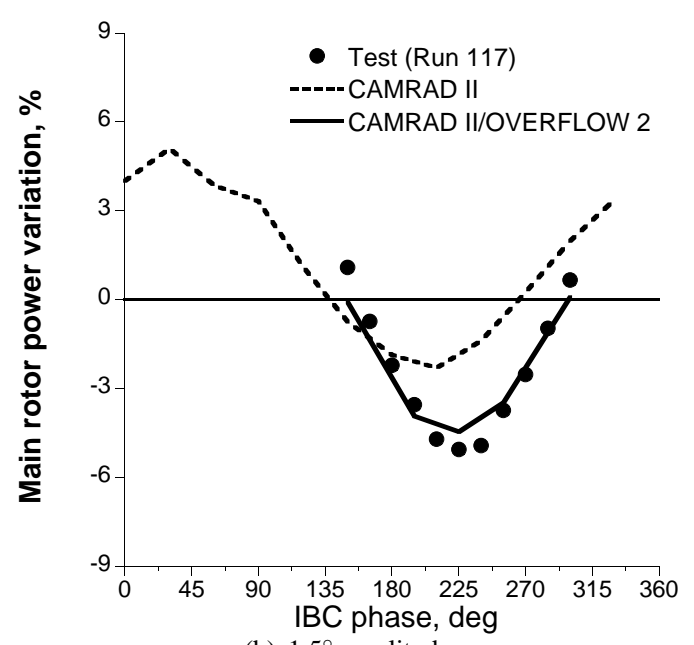

(b) $1.5^{\circ}$ amplitude

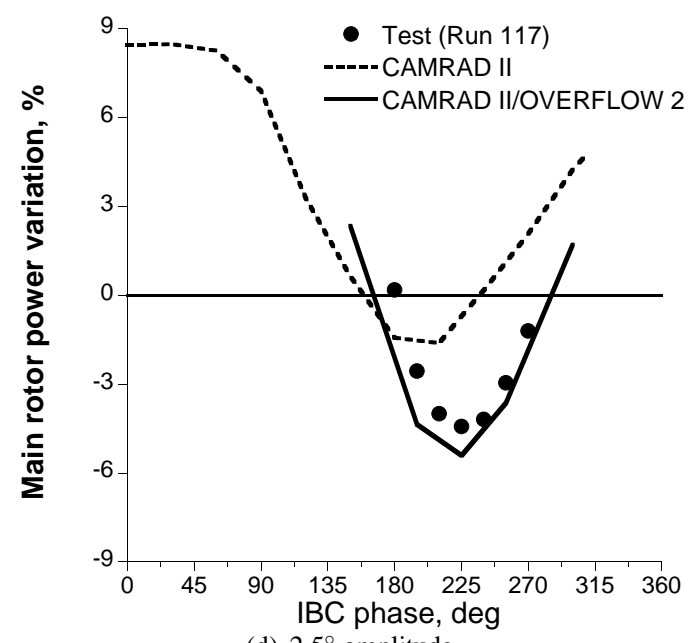

(d) $2.5^{\circ}$ amplitude

Fig. 7: Correlation of main rotor power variation from 2/rev IBC phase sweep, $\mu=0.40$. 

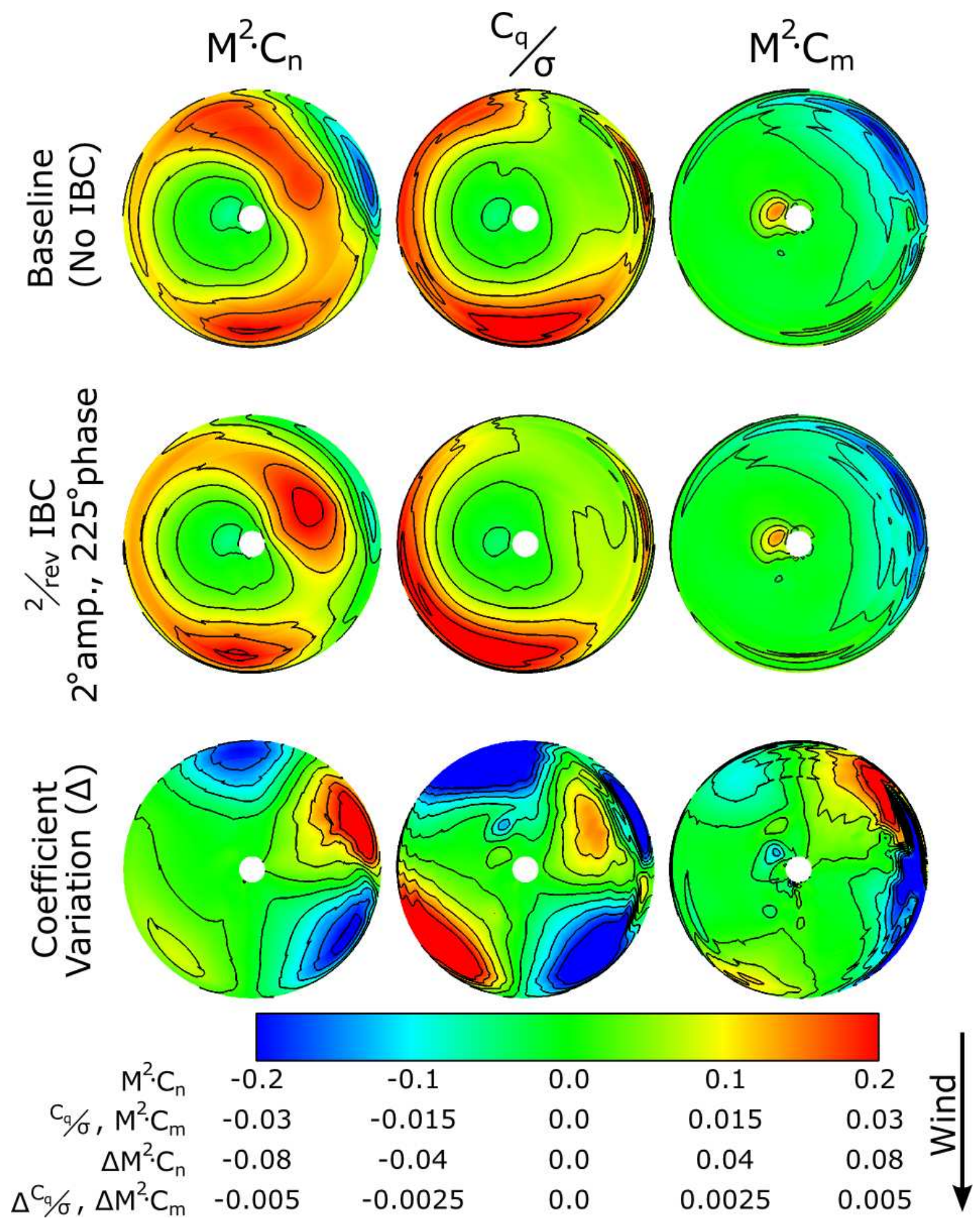

Fig. 8: Blade sectional normal force, torque, and pitching moment with CAMRAD II/OVERFLOW 2 at $\mu=0.40$. 

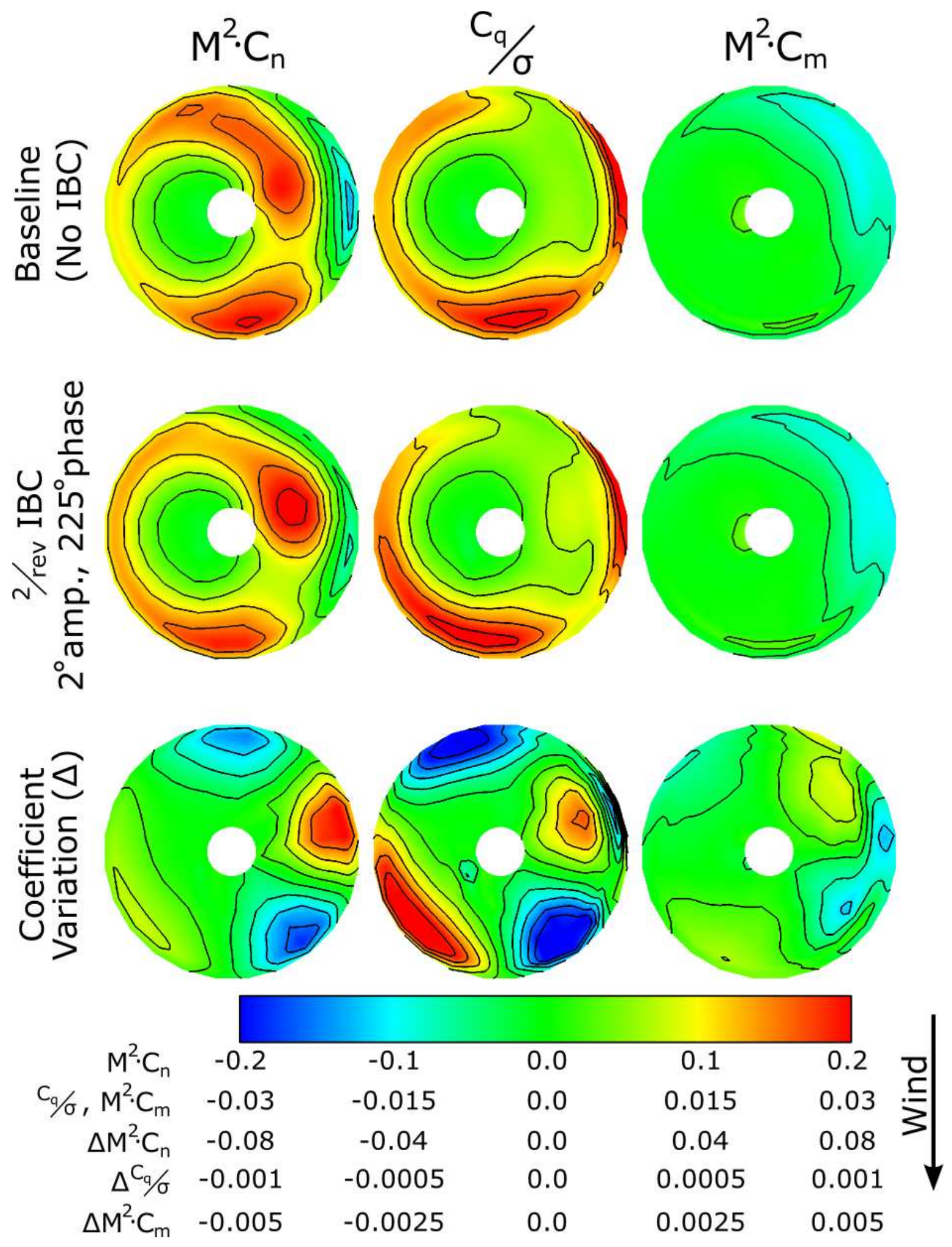

Fig. 9: Blade sectional normal force, torque, and pitching moment with CAMRAD II at $\mu=0.40$. 


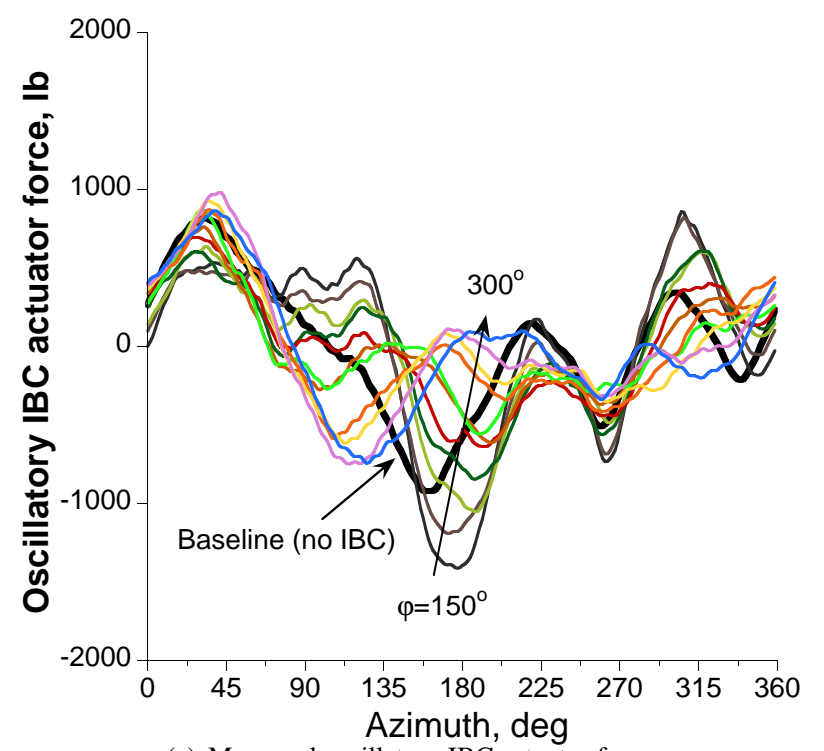

(a) Measured oscillatory IBC actuator force

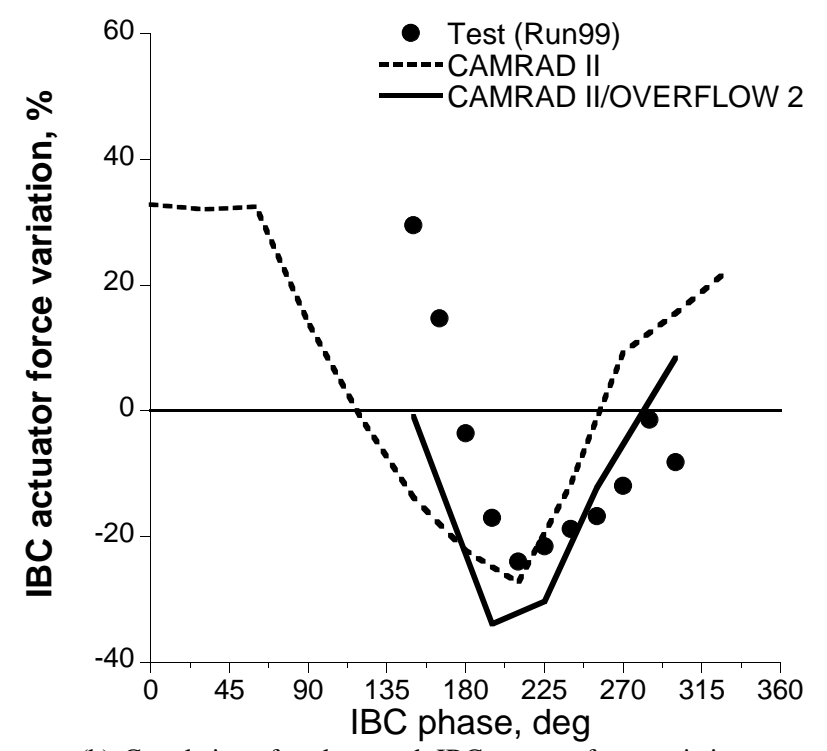

(b) Correlation of peak-to-peak IBC actuator force variation

Fig. 10: IBC actuator force correlation from $2 / \mathrm{rev}$ IBC phase sweep ( $1.5^{\circ}$ amplitude), $\mu=0.35$. 


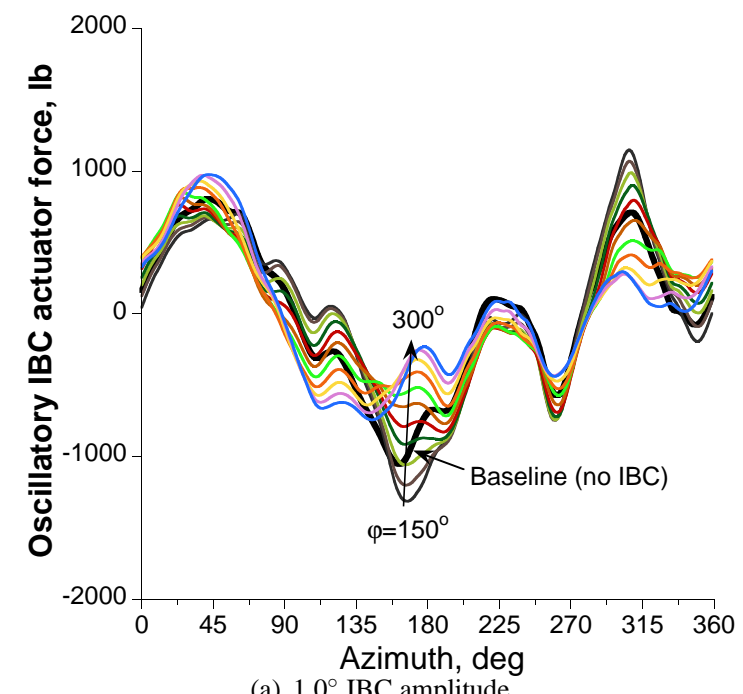

(a) $1.0^{\circ} \mathrm{IBC}$ amplitude

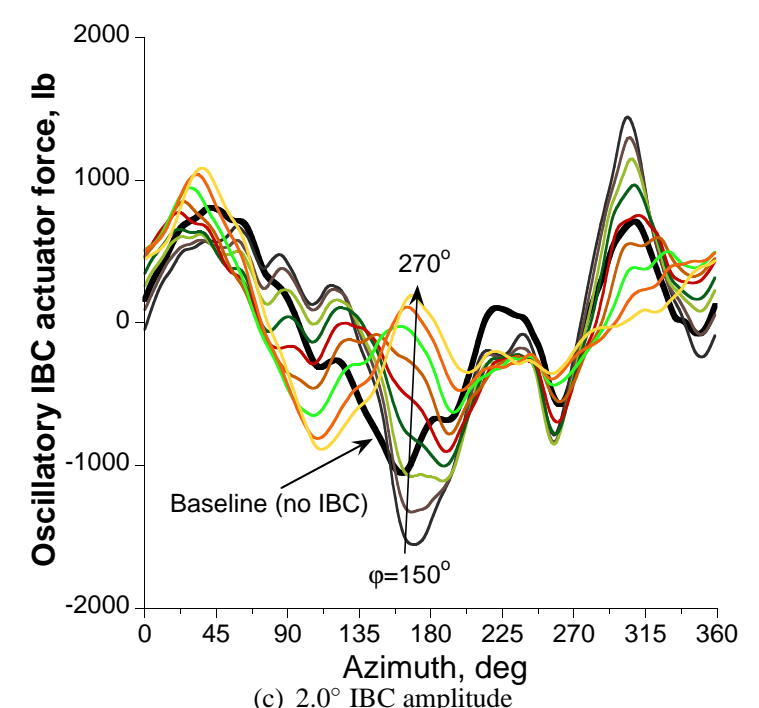

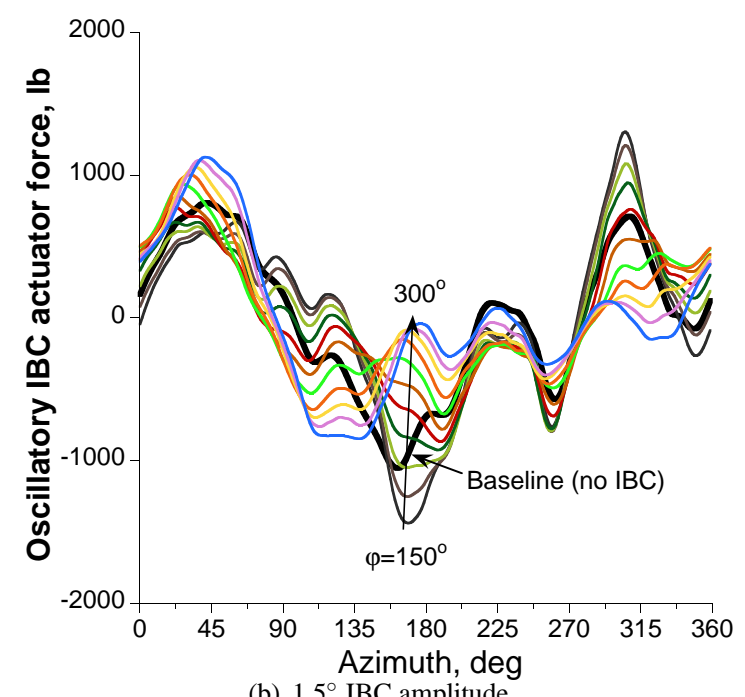

(b) $1.5^{\circ}$ IBC amplitude

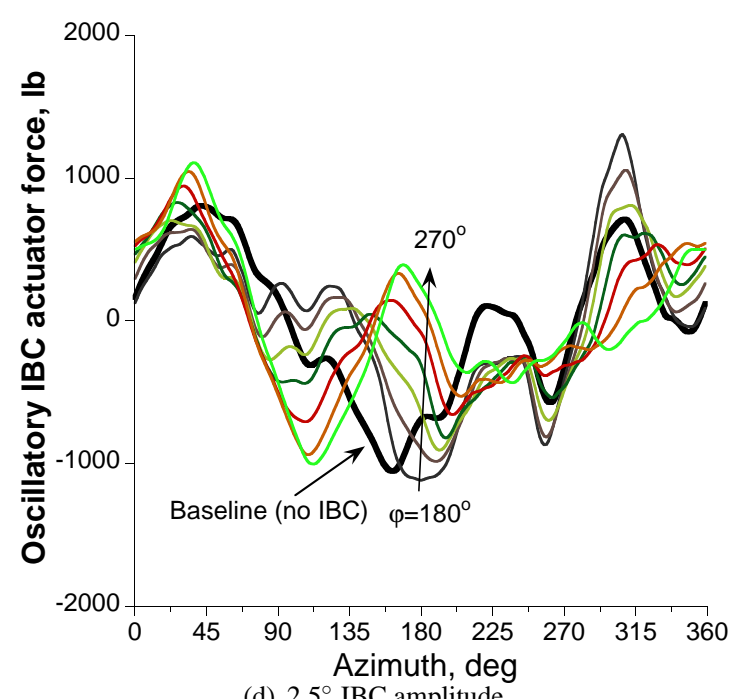

(d) $2.5^{\circ}$ IBC amplitude

Fig. 11: Measured oscillatory IBC actuator force from 2/rev IBC phase sweep, $\mu=0.40$ (Run 117). 


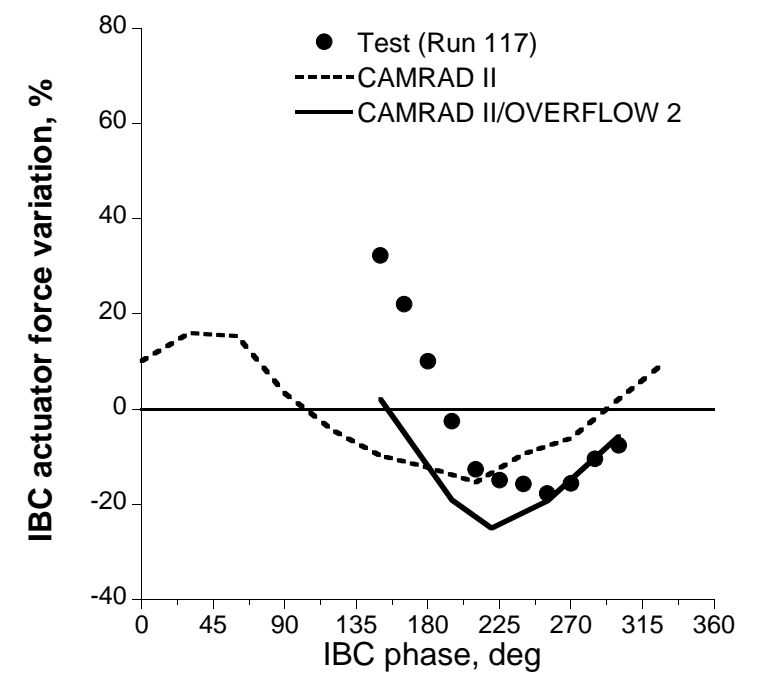

(a) $1.0^{\circ}$ IBC amplitude

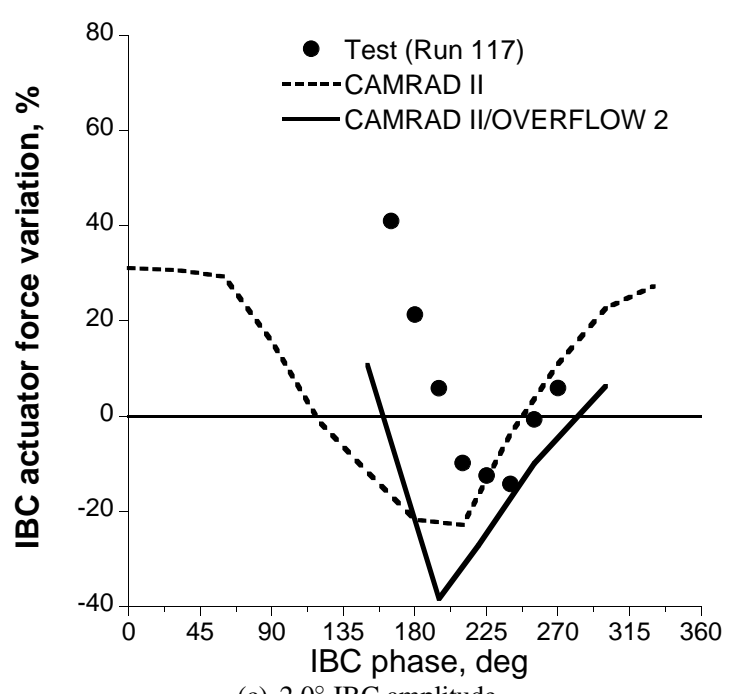

(c) $2.0^{\circ}$ IBC amplitude

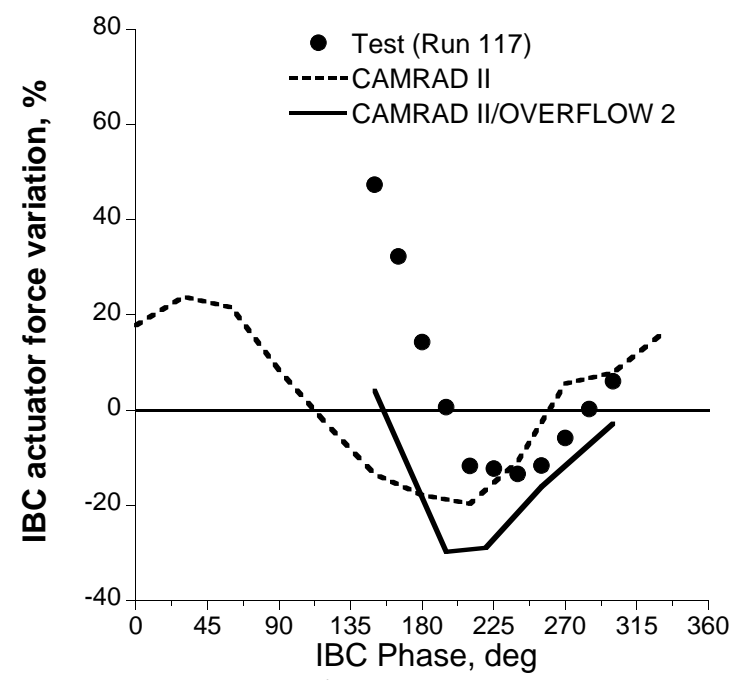

(b) $1.5^{\circ}$ IBC amplitude

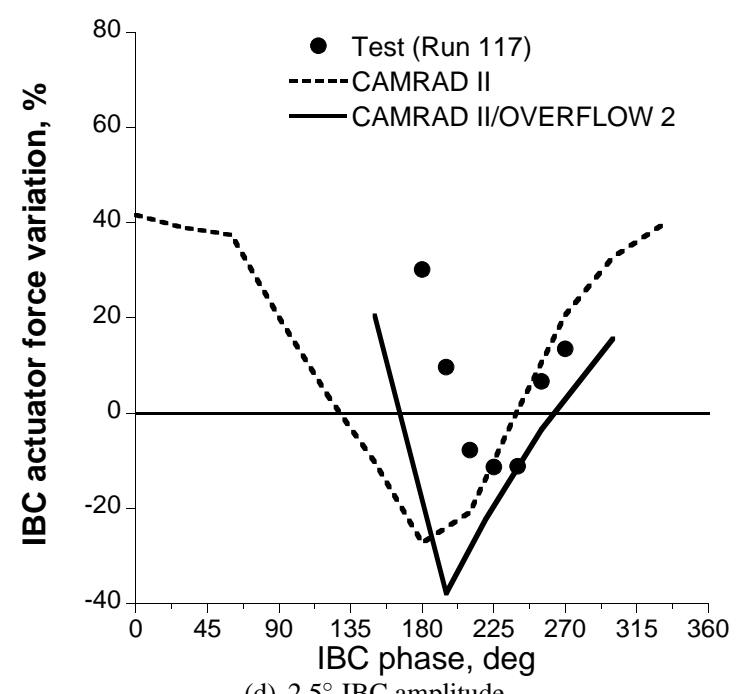

(d) $2.5^{\circ}$ IBC amplitude

Fig. 12: Correlation of peak-to-peak IBC actuator force variation from 2/rev IBC phase sweep, $\mu=0.40$. 


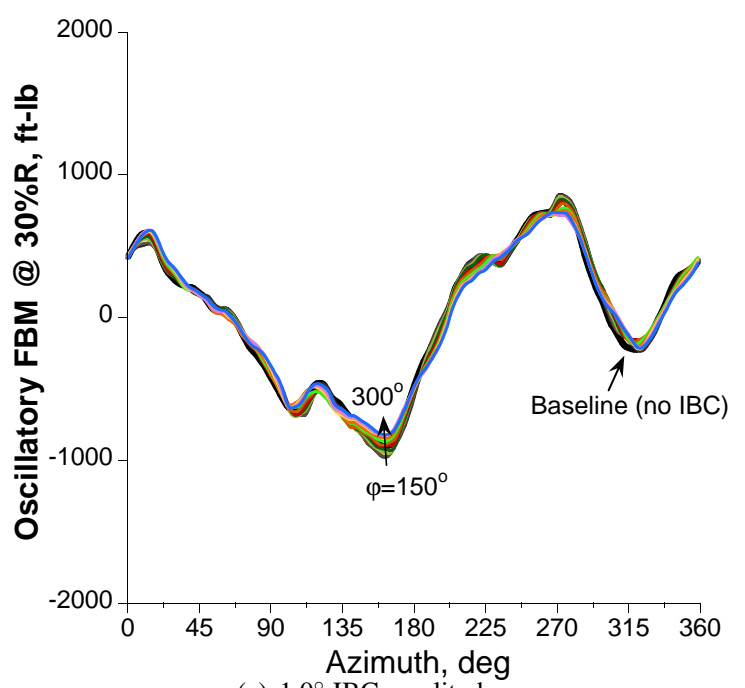

(a) $1.0^{\circ} \mathrm{IBC}$ amplitude

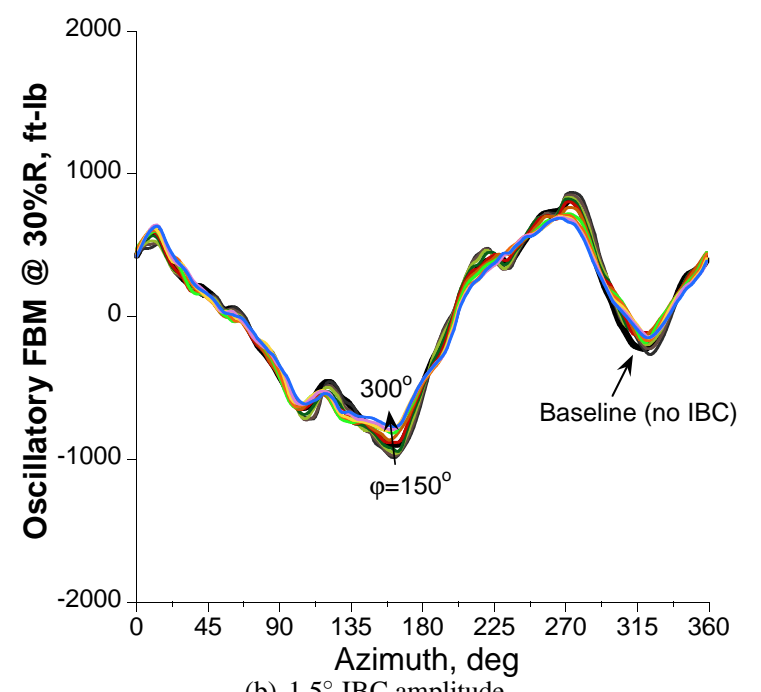

(b) $1.5^{\circ}$ IBC amplitude

Fig. 13: Measured oscillatory flap bending moment @30\%R from 2/rev IBC phase sweep, $\mu=0.40$ (Run 117).

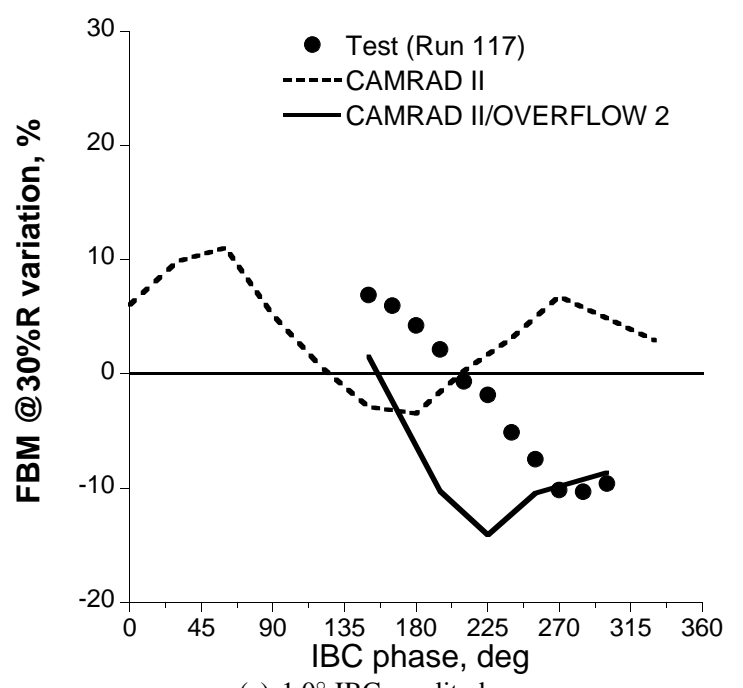

(a) $1.0^{\circ}$ IBC amplitude

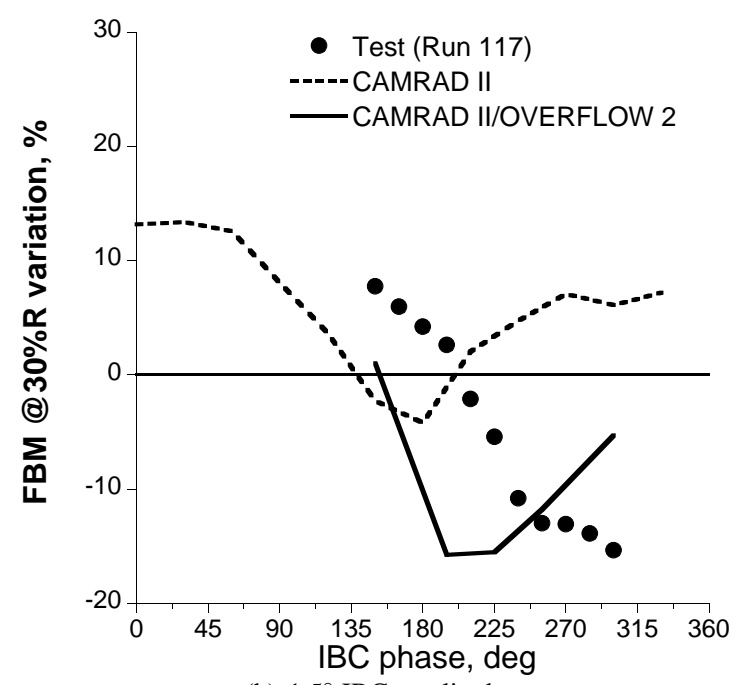

(b) $1.5^{\circ}$ IBC amplitude

Fig. 14: Correlation of peak-to-peak flap bending moment $@ 30 \% \mathrm{R}$ variation from $2 / \mathrm{rev}$ IBC phase sweep, $\mu=0.40$. 


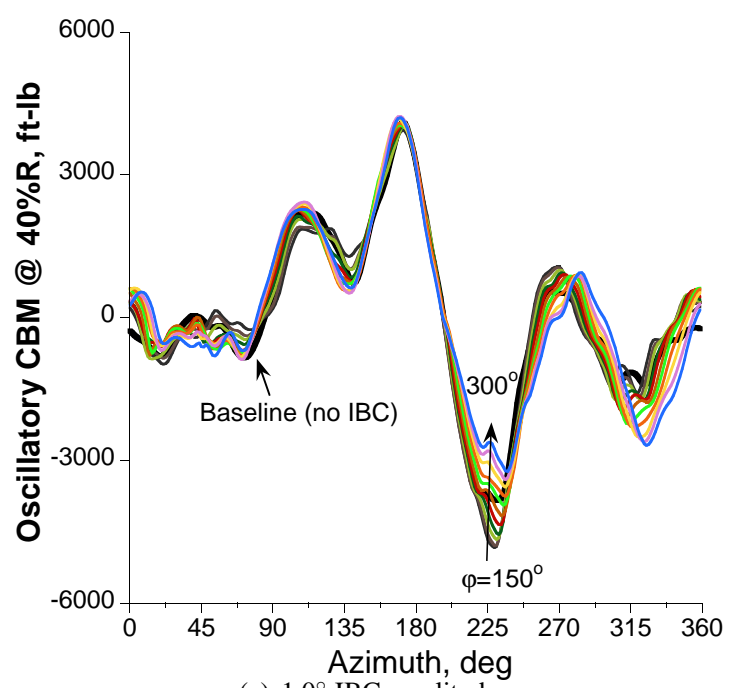

(a) $1.0^{\circ}$ IBC amplitude

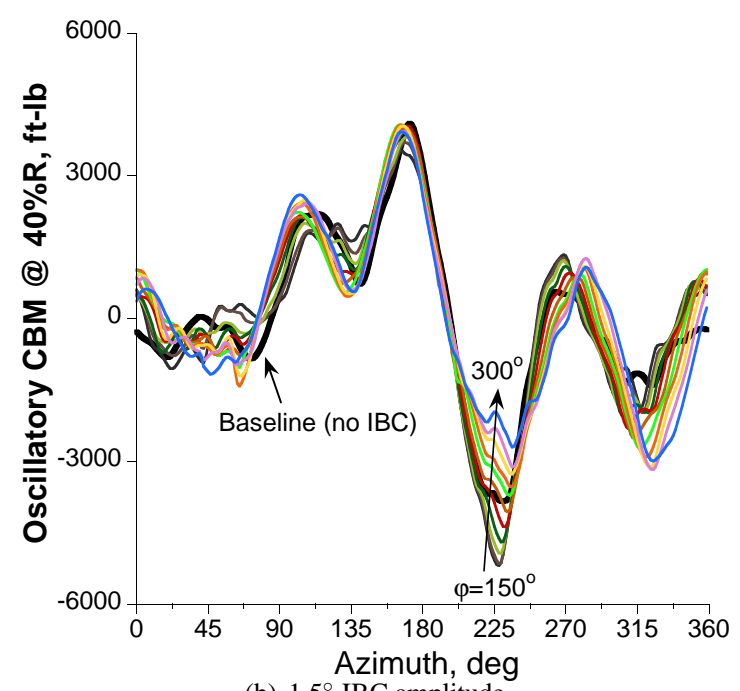

(b) $1.5^{\circ}$ IBC amplitude

Fig. 15: Measured oscillatory chord bending moment @ 40\%R from 2/rev IBC phase sweep, $\mu=0.40$ (Run 117).

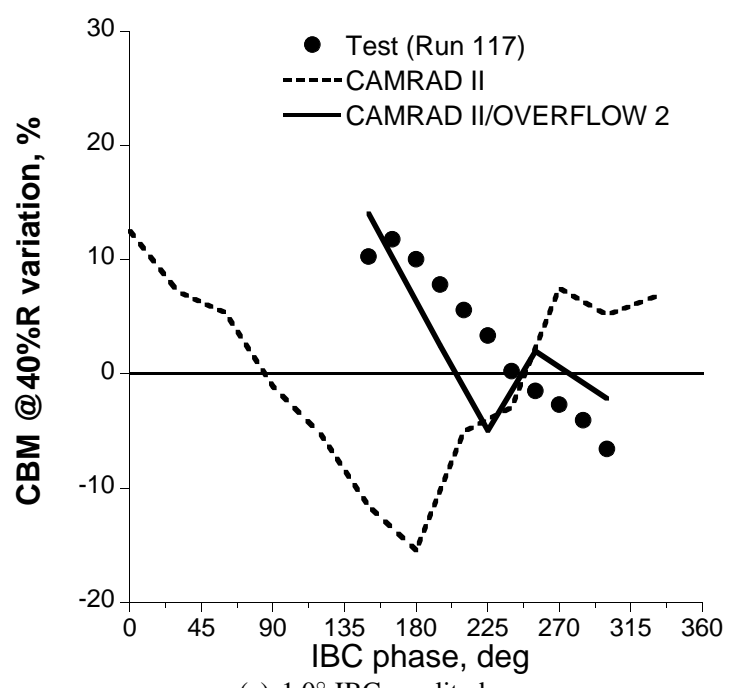

(a) $1.0^{\circ}$ IBC amplitude

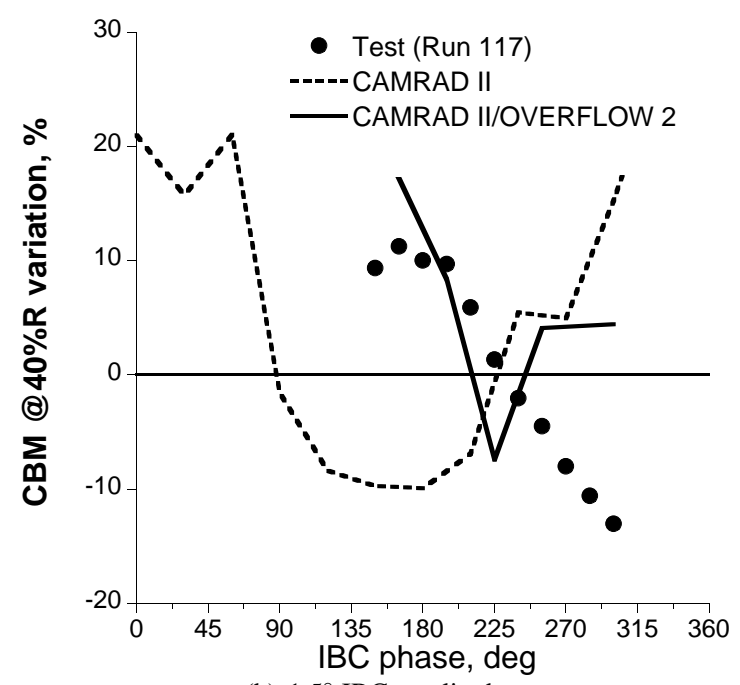

(b) $1.5^{\circ}$ IBC amplitude

Fig. 16: Correlation of peak-to-peak chord bending moment @ 40\%R variation from $2 / \mathrm{rev}$ IBC phase sweep, $\mu=0.40$. 


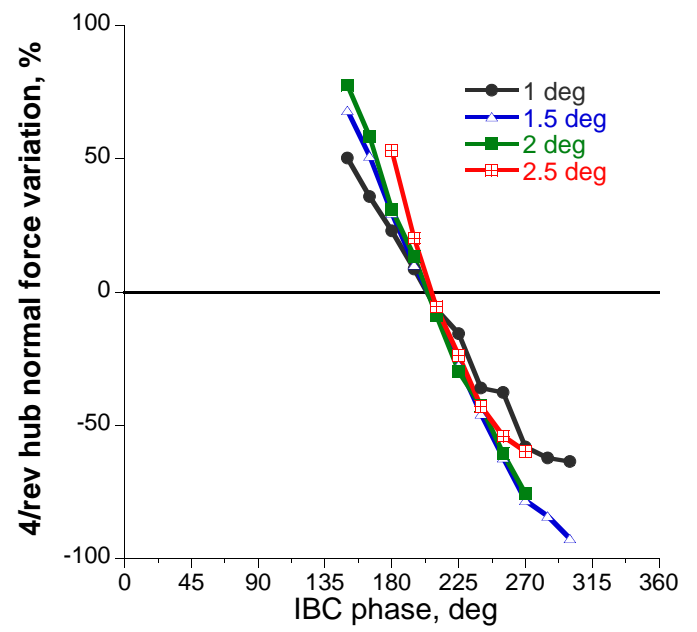

(a) hub normal force

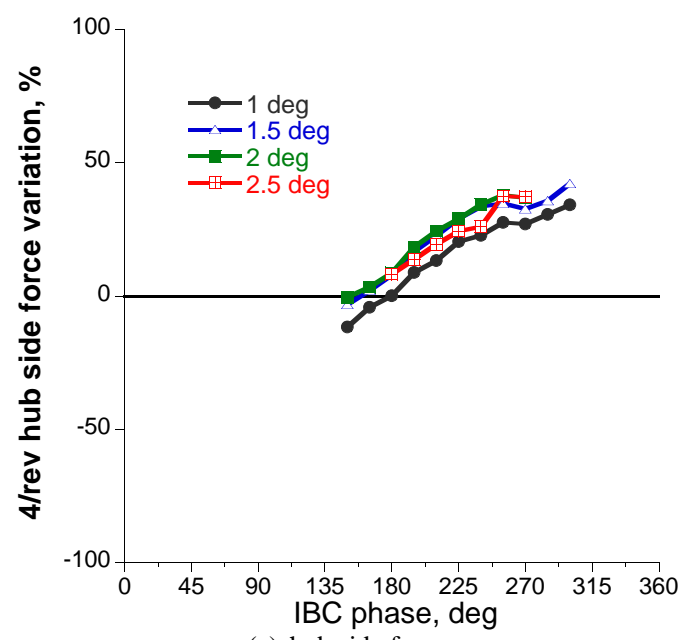

(c) hub side force

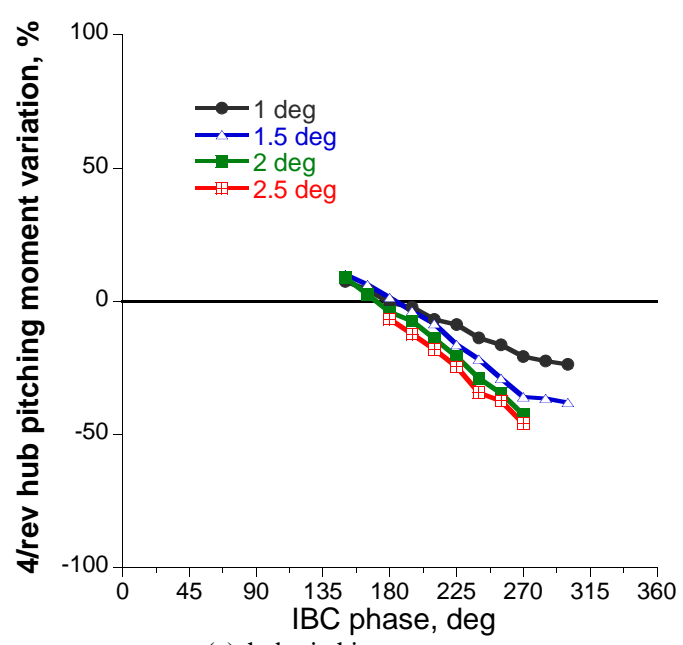

(e) hub pitching moment
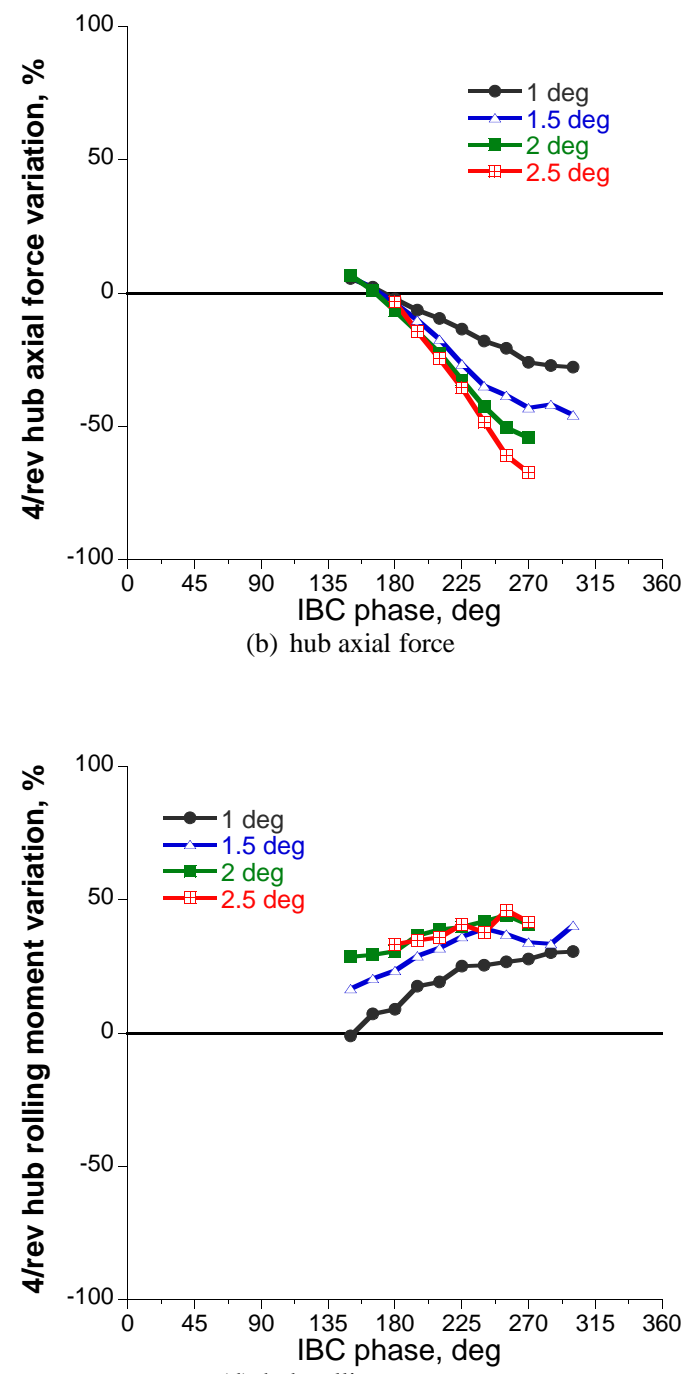

(d) hub rolling moment

Fig. 17: Measured 4/rev hub load variations from 2/rev IBC phase sweep, $\mu=0.40$ (Run 117). 


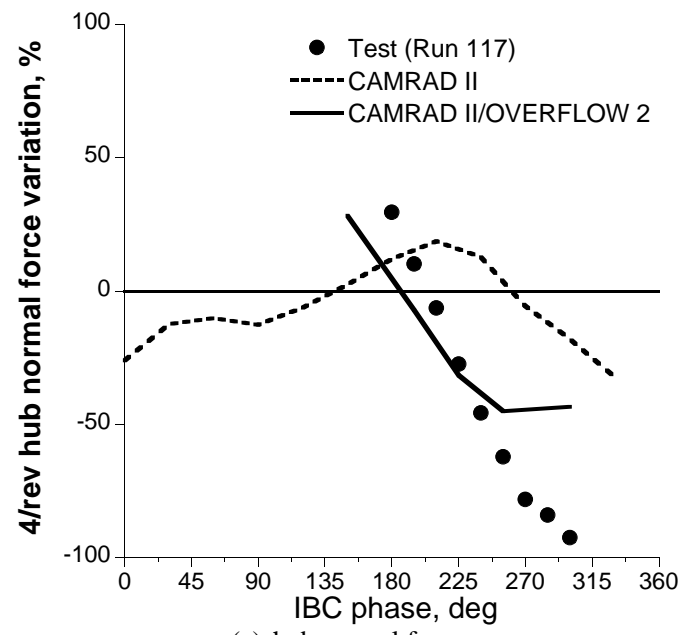

(a) hub normal force

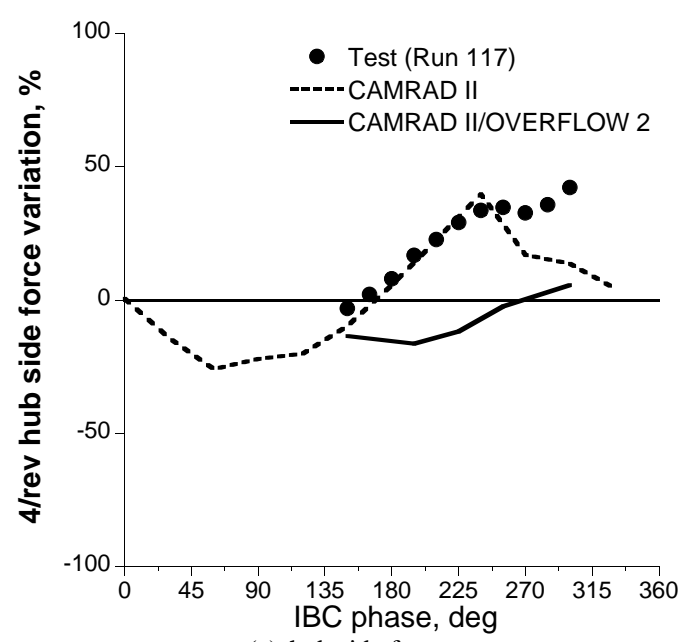

(c) hub side force

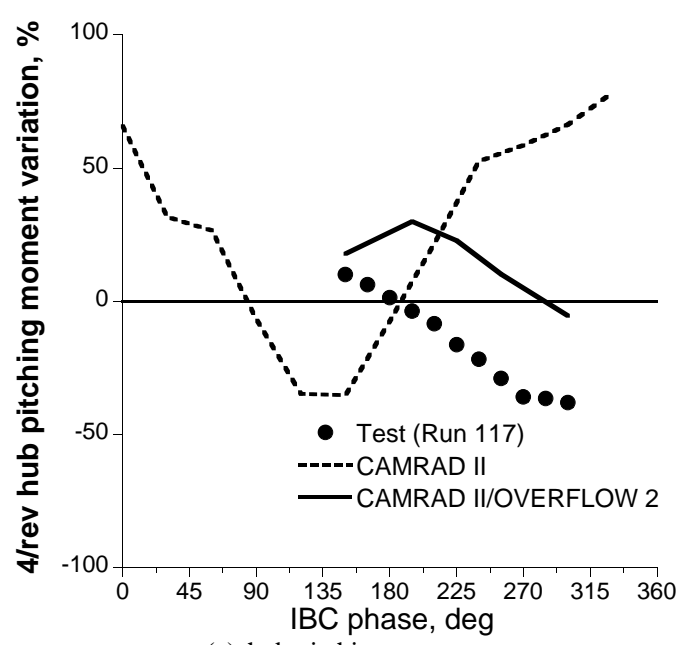

(e) hub pitching moment
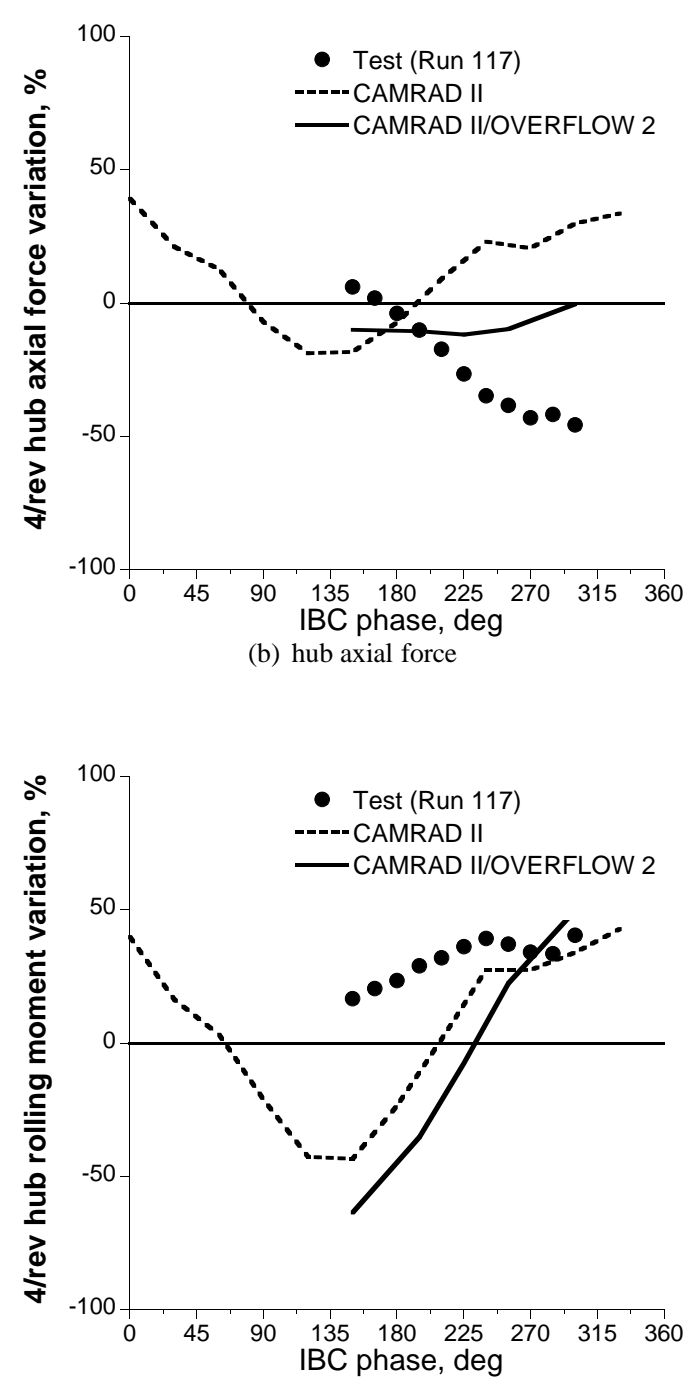

(d) hub rolling moment

Fig. 18: Correlation of 4/rev hub load variations from $2 /$ rev IBC phase sweep ( $1.5^{\circ}$ amplitude), $\mu=0.40$. 